Review/Meta-analyses

\title{
Safety and efficacy of lithium in children and adolescents: A systematic review in bipolar illness
}

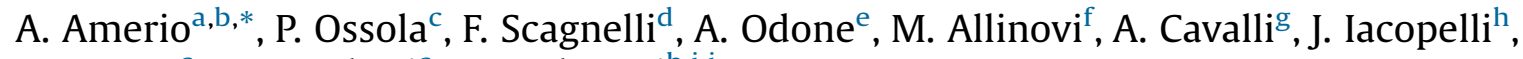 \\ M. Tonna ${ }^{c}$, C. Marchesi ${ }^{\mathrm{c}}$, S.N. Ghaemi ${ }^{\text {b,i,j }}$ \\ a Department of Mental Health, Mental Health Service of Fidenza, Parma, Italy \\ ${ }^{\mathrm{b}}$ Mood Disorders Program, Tufts Medical Center, Boston, MA, USA \\ ${ }^{c}$ Department of Medicine and Surgery, Unit of Neuroscience, University of Parma, Parma, Italy \\ d Department of Mental Health, Mental Health Service of Fiorenzuola, Piacenza, Italy \\ e School of Medicine, Vita-Salute San Raffaele University, Milan, Italy \\ ${ }^{\mathrm{f}}$ Nephrology and Dialysis Unit Meyer Children's Hospital, Florence, Italy \\ ${ }^{g}$ Neuroscience Centre of Excellence, Meyer Children's Hospital, Florence, Italy \\ ${ }^{\mathrm{h}}$ Department of Health Sciences, A. Meyer Children's University Hospital, Florence, Italy \\ ${ }^{i}$ Department of Psychiatry, Tufts University Medical School, Boston, MA, USA \\ ${ }^{\mathrm{j}}$ Novartis Institutes for Biomedical Research, Translational Medicine-Neuroscience, Cambridge, MA, USA
}

\section{A R T I C L E I N F O}

\section{Article history:}

Received 19 April 2018

Received in revised form 30 July 2018

Accepted 31 July 2018

Available online 18 August 2018

\section{Keywords:}

Lithium

Children

Adolescents

Bipolar

Depression

Safety

Efficacy

\begin{abstract}
A B S T R A C T
Introduction: Many clinicians are reluctant to use traditional mood-stabilizing agents, especially lithium, in children and adolescents. This review examined the evidence for lithium's safety and efficacy in this population.

Methods: A systematic review was conducted on the use of lithium in children and adolescents with bipolar disorder (BD). Relevant papers published through June $30^{\text {th }} 2018$ were identified searching the electronic databases MEDLINE, Embase, PsycINFO and the Cochrane Library.

Results: 30 articles met inclusion criteria, including 12 randomized controlled trials (RCTs). Findings from RCTs demonstrate efficacy for acute mania in up to $50 \%$ of patients, and evidence of long-term maintenance efficacy. Lithium was generally safe, at least in the short term, with most common side effects being gastrointestinal, polyuria, or headache. Only a minority of patients experienced hypothyroidism. No cases of acute kidney injury or chronic kidney disease were reported.

Conclusions: Though the available literature is mostly short-term, there is evidence that lithium monotherapy is reasonably safe and effective in children and adolescents, specifically for acute mania and for prevention of mood episodes.
\end{abstract}

(C) 2018 Elsevier Masson SAS. All rights reserved.

\section{Introduction}

The diagnosis of bipolar disorder (BD) in children and adolescents has been a controversial topic [1], with much concern about risks of treating it [2], with concerns about the harms of antipsychotic agents in particular [3]. An alternative to antipsychotic agents would be mood-stabilizing drugs like lithium, yet

\footnotetext{
* Corresponding author at: Department of Mental Health, Mental Health Service of Fidenza, Via Berenini 153, Fidenza, Parma, Italy.

E-mail addresses: andrea.amerio@studenti.unipr.it (A. Amerio), ossola.paolo@gmail.com (P. Ossola),scagnelli.fra@libero.it (F. Scagnelli), anna.odone@mail.harvard.edu (A. Odone), marco.allinovi@gmail.com (M. Allinovi) , a.cavalli@meyer.it (A. Cavalli), jessica.iacopelli@gmail.com (J. Iacopelli), mtonna@ausl.pr.it (M. Tonna), carlo.marchesi@unipr.it (C. Marchesi), nassir.ghaemi@tufts.edu (S.N. Ghaemi).
}

clinicians also are reluctant to use that agent, especially with apprehension regarding cognitive side effects [4], as well as about long-term medical risks, such as hypothyroidism and chronic renal insufficiency [5]. Further, many clinicians seem to be sceptical about the efficacy of lithium in children.

This paper seeks to shed light on these concerns, with the first systematic review on the safety and efficacy of lithium in children and adolescents with BD.

\section{Materials and methods}

As done before [6,7], this review was conducted according to methods recommended by the Cochrane Collaboration and the Preferred Reporting Items for Systematic Reviews and MetaAnalyses (PRISMA) guidelines [8,9]. 


\subsection{Information sources and search strategy}

Studies were identified searching the electronic databases MEDLINE, Embase, PsycINFO and the Cochrane Library. We combined the search strategy of free text terms and exploded MESH headings for the topic of treatment with lithium in children and adolescents combined as following: ((()(Lithium) OR Lithium carbonate) OR Lithium carbonate[MeSH Terms])) AND (((Children) OR Adolescent) OR Adolescent[MeSH Terms])) AND (((()((Bipolar disorder) OR BD) OR Bipolar) OR Manic depressive disorder) OR Manic depressive) OR Manic) OR Bipolar disorder[MeSH Terms])) AND ((( (treatment*) OR therap*) OR pharmacotherap*) OR Therapeutics[MeSH Terms]). The strategy was first developed in MEDLINE and then adapted for use in the other databases (Appendix A in Supplementary material). Studies published in English through June $30^{\text {th }} 2018$ were included. In addition, further studies were retrieved from reference listing of relevant articles and consultation with experts in the field.

\subsection{Inclusion criteria}

\subsubsection{Study population and study design}

We considered studies that included children and adolescents with BD treated with lithium both in monotherapy and in combination with others psychotropic drugs. BD was considered if diagnostic criteria used were specified. Studies conducted on youths with different disorders than BD (e.g. dysphoric mood dysregulation disorder) were excluded (i.e. [10-12]:). Participants of both sexes younger than 18 years of age were considered. Studies conducted on subjects with physical comorbidities such as epilepsy were excluded as non-representative of the study population [13].

Among hospital-based studies, inpatients, day-hospital and outpatient subjects were included, while emergency care records were excluded as non-representative. All experimental and observational study designs were included apart from case reports and case series. Narrative and systematic reviews, letters to the editor, and book chapters were excluded.

\subsubsection{Outcomes}

The primary outcome was lithium effectiveness in children and adolescents with BD. Secondary outcomes were i) starting dose and dosing strategy, ii) brain-to-serum lithium association, and iii) safety and tolerability of lithium.

\subsubsection{Study selection and data extraction}

Identified studies were independently reviewed for eligibility by two authors (AA, FS) in a two-step process: A first screening was performed based on title and abstract, and then full texts were retrieved for a second screening. At both stages disagreements by reviewers were resolved by consensus. Data were extracted by two authors (AA, FS) and supervised by a third author (SNG) using an ad-hoc developed data extraction spreadsheet. The data extraction spreadsheet was piloted on 10 randomly selected papers and modified accordingly.

\section{Results}

Two hundred and twelve potential studies were identified from the selected databases and after cross-checking references of relevant articles. After removing duplicates, 152 articles were retrieved. Studies were screened and selected on the basis of pre-specified inclusion and exclusion criteria (Fig. 1). The search identified 30 articles that were included in the systematic review.

\subsection{Included studies}

The characteristics of included studies are reported in Table 1. Twelve (40\%) of the 30 studies were randomized controlled trials (RCTs) of which only one was longer than 6 months in duration. Most studies ( $n=19,63 \%$ ) were short-term ( 8 weeks or less), while 4 studies (13\%) provided long-term data of 6 months or longer. The smallest study included 6 subjects while the largest considered a sample of 279 subjects. The majority of the studies were conducted in North America $(\mathrm{N}=28,93 \%)$. In all the considered studies, diagnosis were based on the Diagnostic and Statistical Manual (DSM) criteria and were established using validated assessment scales (Table 1).

\subsection{Outcomes}

Selected studies included children and adolescents with BD treated with lithium. Both lithium monotherapy and lithium in combination with adjunctive agents were included. Data about starting dose and dosing strategy, brain-to-serum lithium association, safety and tolerability were also reported (Table 2).

\section{Bipolar illness}

Thirty studies assessed the use of lithium in children and adolescents with BD (Table 2 ). The majority of the selected studies $(\mathrm{N}=22 / 30,73 \%)$ were conducted on BD patients treated with lithium monotherapy. Eleven studies (37\%) were specific for BD-I patients.

\subsection{Lithium monotherapy}

\subsubsection{Manic or mixed episodes}

Three RCTs reported improvements in manic or mixed symptoms and overall functioning in manic BD children and adolescents with lithium treatment [14,20,21]. Over $50 \%$ of patients met response and remission criteria in one out of three of the cited studies [14]. These results were supported by three prospective non-randomized cohort studies [18,22,23] and one retrospective cohort study [24]. No significant difference in exacerbation rates between subjects treated with lithium and those switched to placebo was detected in only one RCT with a very short stabilization period (two weeks) [25].

Considering bipolar subgroups, lithium effectiveness for manic symptoms was greater in adolescent-onset compared to prepubertal-onset patients in one study [23]. Manic adolescents with comorbid attention deficit hyperactivity disorder (ADHD) showed less robust and slower improvement with lithium compared to non-comorbid patients, both in a randomized and in a nonrandomized trial $[26,27]$. In patients with substance abuse and BD, lithium was an effective for both conditions in one RCT [15].

\subsubsection{Depressive episodes}

A 6-week prospective non-randomized cohort study in BD-I depressed children and adolescents treated with lithium reported response and remission rates of $48 \%$ and $30 \%$, respectively, with a large reduction in Children's Depression Rating Scale-Revised (CDRS-R) scores (standardized effect size Cohen's d = 1.7) [28].

\subsubsection{Prophylaxis}

Three prospective non-randomized cohort studies reported long-term positive response to lithium treatment [29,30], especially in those who responded to acute treatment with lithium [31].

In a 18-month prospective non-randomized cohort study, 35\% $(\mathrm{N}=13 / 37)$ of patients who discontinued prophylactic lithium therapy showed nearly three times higher relapse rates compared 


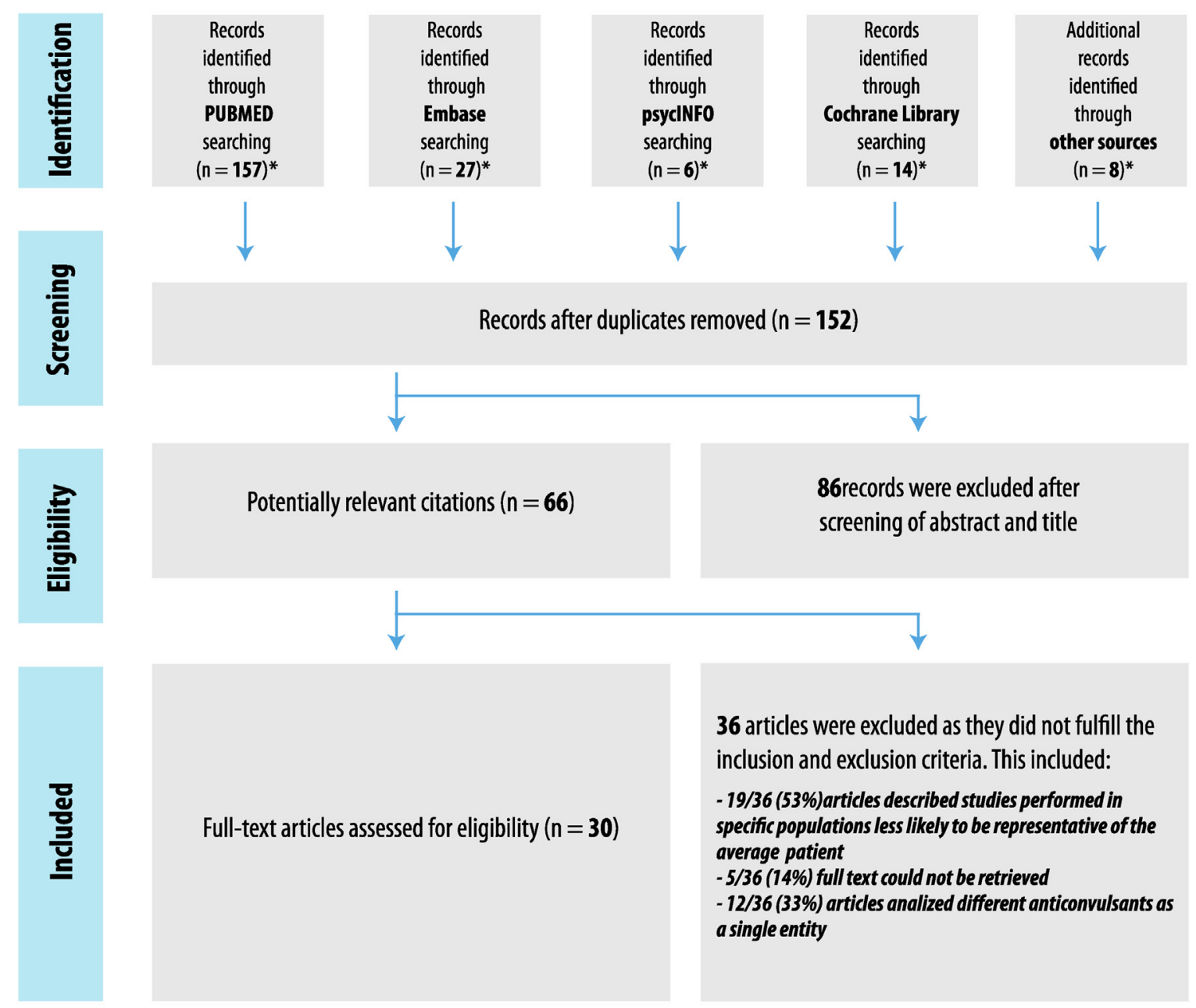

Fig. 1. Flow diagram of selected articles.

*Search strategy limited to June 2018, English language, human subjects younger than 18 years old, and clinical trial.

to patients who continued lithium prophylaxis [30]. Early relapse was associated with a greater risk of future relapse.

In contrast, an Indian prospective non-randomized cohort study found that $64 \%(\mathrm{~N}=16 / 25)$ of lithium-treated subjects relapsed after $18 \pm 16.4$ months (mean total follow-up duration $51.6 \pm 4.1$ months). The majority of the relapses $(72.4 \%)$ occurred during prophylactic treatment. $28 \%(\mathrm{~N}=7 / 25)$ and $36 \%(\mathrm{~N}=9 / 25)$ of relapsing patients had single and multiple relapses respectively, with manic episodes being the most common polarity $(N=14 / 25$, 58\%) [32].

\subsubsection{Offspring of manic-depressive patients}

In a small RCT, $33 \%(\mathrm{~N}=2 / 6)$ children, who met DSM-III criteria for $\mathrm{BD}$ and were offspring of manic-depressive patients, responded to lithium on both child and parent ratings and showed augmentation of evoked potentials (EPs) similar to what is seen in adults treated with lithium [33].

\subsubsection{Lithium monotherapy vs. other psychotropic drugs}

Five RCTs compared lithium monotherapy to other mood stabilizers or antipsychotics [34-38]. In a 18-month RCT, divalproex was not found to be superior to lithium as maintenance treatment in BD youths who had been stabilized on combined lithium plus divalproex for four weeks [34].
In a prospective non-randomized cohort study, lithium, divalproex, and carbamazepine all showed a large and similar effect size in treatment of acute manic or mixed episodes [36].

Compared to antipsychotics for initial treatment of acute manic or mixed episode in children and adolescents, risperidone was more efficacious than mood stabilizers but had more metabolic side effects [35,37]. Also, risperidone was more effective than lithium or divalproex for children with BD-I who were nonresponders or partial responders to another prior antimanic agent [38].

\subsection{Lithium in combination with adjunctive agents}

As in adults, children and adolescents with BD frequently required long-term combination therapy [39]. Therefore, adherence became important [19]. A 6-month prospective nonrandomized cohort study demonstrated that lithium or divalproex plus risperidone were equally efficacious and safe for manic and mixed symptoms in pediatric mania [40]. In psychotic mania, one study found that adjunctive antipsychotic medication needed to be maintained longer than 4 weeks in the majority of adolescents [17].

As demonstrated by two prospective non-randomized cohort studies, the combination of lithium and divalproex was effective in treating acute manic and depressive symptoms in juvenile BD and 
Table 1

Studies that met inclusion criteria for systematic review.

\begin{tabular}{|c|c|c|c|c|c|c|}
\hline References & Study design & Country & Study population & $\mathrm{N}$ at entry/ Retained & $\begin{array}{l}\text { Diagnostic } \\
\text { assessment }\end{array}$ & Outcomes \\
\hline [29] & $\begin{array}{l}\text { Prospective } \\
\text { non- } \\
\text { randomized } \\
\text { cohort }\end{array}$ & USA & $\begin{array}{l}\text { Pts }(\mathrm{n}=59 ; \text { mean } \\
\text { age }=11.4)\end{array}$ & $\begin{array}{l}\text { 196, enrolled (59, bipolar; 29, depression; } \\
\text { 11, EUCD; 19, ADD; 7, offspring of } \\
\text { Li + responder; 33, CD; 8, ADD/affective; } 9 \text {, } \\
\text { affective/aggressive/explosive; } 21 \text {, } \\
\text { Developmental disorder) }\end{array}$ & DSM & Lithium effectiveness (clinical criteria) \\
\hline [29] & $\begin{array}{l}\text { Prospective } \\
\text { non- } \\
\text { randomized } \\
\text { cohort }\end{array}$ & USA & $\begin{array}{l}\mathrm{BD}(\mathrm{n}=107 ; \text { mean } \\
\text { age }=10.49)\end{array}$ & 107, completed & $\begin{array}{l}\text { K-SADS; } \\
\text { DSM-IV }\end{array}$ & $\begin{array}{l}\text { Lithium effectiveness: CDRS-R } \leq 40 \text {, } \\
\text { YMRS } \leq 12.5 \text {, CGAS } \geq 51 \text { (for } 4 \\
\text { consecutive weeks) [Remission]; } \mathrm{Li}+\text { and } \\
\text { DVPX serum level }\end{array}$ \\
\hline$[41]$ & $\begin{array}{l}\text { Prospective } \\
\text { non- } \\
\text { randomized } \\
\text { cohort }\end{array}$ & USA & $\begin{array}{l}\mathrm{BD}(\mathrm{n}=90 ; \text { mean } \\
\text { age }=10.9)\end{array}$ & $\begin{array}{l}\text { 109, enrolled; } 90 \text {, completed at least one } \\
\text { week }\end{array}$ & $\begin{array}{l}\text { K-SADS, K- } \\
\text { SADS-E, K- } \\
\text { SADS-PL; } \\
\text { DSM-IV }\end{array}$ & $\begin{array}{l}\text { Lithium effectiveness: } \downarrow \text { YMRS } 50 \% \text {, } \\
\text { CGI } \leq 2 \text { [Response]; CDRS-R } \leq 40 \text {, } \\
\text { YMRS } \leq 12.5, \text { CGAS } \geq 51 \text { (for } 4 \\
\text { consecutive weeks) [Remission] }\end{array}$ \\
\hline [34] & RCT & USA & $\begin{array}{l}\mathrm{BD}(\mathrm{n}=60 ; \text { mean } \\
\text { age }=10.8)\end{array}$ & $\begin{array}{l}60 \text {, treated ( } 30, \text { DVPX; } 30 \mathrm{Li}+) \text { after } \\
\text { achieving remission on open-label DVPX- } \\
\mathrm{Li}+\text { combination treatment }\end{array}$ & DSM-IV & $\begin{array}{l}\text { Lithium effectiveness: CDRS-R } \leq 40 \text {, } \\
\text { YMRS } \leq 12.5 \text {, CGAS } \geq 51 \text { [Remission] }\end{array}$ \\
\hline [42] & $\begin{array}{l}\text { Prospective } \\
\text { non- } \\
\text { randomized } \\
\text { cohort }\end{array}$ & USA & $\begin{array}{l}\mathrm{BD}(\mathrm{n}=38 \text { subjects; } \\
\text { mean age }=10.3)\end{array}$ & $\begin{array}{l}\text { 40, enrolled; } 38 \text {, completed at least one } \\
\text { week ( } 19 \mathrm{Li}+\text { monotherapy, } 19 \text { DVPX } \\
\text { monotherapy during the randomized } \\
\text { maintenance monotherapy trial) }\end{array}$ & $\begin{array}{l}\text { K-SADS; } \\
\text { DSM-IV }\end{array}$ & $\begin{array}{l}\text { Lithium effectiveness: CDRS-R } \leq 40 \text {, } \\
\text { YMRS } \leq 12.5 \text {, CGAS } \geq 51 \text { [Remission] }\end{array}$ \\
\hline [43] & $\mathrm{RCT}$ & USA & $\begin{array}{l}\mathrm{BD}-\mathrm{I}(\mathrm{n}=39, \text { manic or } \\
\text { mixed phase; mean } \\
\text { age }=11.8)\end{array}$ & $\begin{array}{l}\text { 39, randomly assigned to Arm I ( } \mathrm{Li}+ \\
600 \mathrm{mg} / \text { day) or Arm II ( } \mathrm{Li}+, 900 \mathrm{mg} / \text { day })\end{array}$ & $\begin{array}{l}\text { K-SADS-PL, } \\
\text { YMRS } \geq 20 \\
\text { WASI } \geq 70 \\
\text { DSM-IV }\end{array}$ & $\mathrm{Li}+$ serum level \\
\hline [14] & $\mathrm{RCT}$ & USA & $\begin{array}{l}\mathrm{BD}-\mathrm{I}(\mathrm{n}=60 \text {, manic or } \\
\text { mixed phase; mean } \\
\text { age }=12.6)\end{array}$ & $\begin{array}{l}\text { 61, enrolled; } 60 \text {, completed at least } 1 \\
\text { week of score (ARM I: } 15 \text {, completed, Li+ } \\
300 \mathrm{mg} / \text { twice a day as starting dose; ARM } \\
\text { II, } 13 \text { completed, and ARM III, } 12 \\
\text { completed, Li+ } 300 \mathrm{mg} / \text { thrice a day as } \\
\text { starting dose) }\end{array}$ & DSM-IV & $\begin{array}{l}\text { Lithium effectiveness: } \downarrow \text { YMRS: } \geq 50 \% \text {, } \\
\text { CGI } \leq 2 \text { [Response]; } \downarrow \text { YMRS } 25-50 \% \text {, } \\
\text { CGI } \leq 3 \text { [Partial response]; CGI } \geq 4 \text { or } \\
\downarrow \text { YMRS }<25 \% \text { or inability to tolerate a dose } \\
\text { of } 600 \mathrm{mg} / \text { day Li }+ \text { [Non responders] }\end{array}$ \\
\hline [31] & $\begin{array}{l}\text { Prospective } \\
\text { non- } \\
\text { randomized } \\
\text { cohort }\end{array}$ & USA & $\begin{array}{l}\text { BD-I ( } \mathrm{n}=41 \text {, manic or } \\
\text { mixed phase; mean age } \\
11.8)\end{array}$ & $\begin{array}{l}\text { 105, screened for Phase I; 61, enrolled in } \\
\text { Phase I; 41, completed Phase I and were } \\
\text { enrolled in Phase II }\end{array}$ & $\begin{array}{l}\text { YMRS; DSM- } \\
\text { IV }\end{array}$ & $\begin{array}{l}\text { Lithium effectiveness: } \downarrow \text { YMRS: } \geq 50 \% \text {, } \\
\text { CGI } \leq 2 \text { [Response]; } \downarrow \text { YMRS } 25-50 \%, \\
\text { CGI } \leq 3 \text { [Partial response]; YMRS } \leq 12 \text {, } \\
\text { CGI } \leq 2 \text { [Remission] }\end{array}$ \\
\hline [20] & RCT & USA & $\begin{array}{l}\mathrm{BD}-\mathrm{I}(\mathrm{n}=58, \text { manic or } \\
\text { mixed phase; mean age } \\
11.3)\end{array}$ & $\begin{array}{l}\text { 81, enrolled ( } 53, \mathrm{Li}+; 28 \text {, placebo),; } 58, \\
\text { completed }\end{array}$ & $\begin{array}{l}\text { K-SADS-PL; } \\
\text { DSM-IV }\end{array}$ & $\begin{array}{l}\text { Lithium effectiveness: } \downarrow \text { YMRS: } \geq 50 \% \text {, } \\
\text { CGI-I } \leq 2 \text { [Response]; YMRS } \leq 12, \text { CGI-S } \leq 2 \\
\text { [Remission] }\end{array}$ \\
\hline$[15,16]$ & $\mathrm{RCT}$ & USA & $\begin{array}{l}\text { BD-SDD }(n=25 \\
\text { enrolled; mean } \\
\text { age }=16.3)\end{array}$ & $\begin{array}{l}25 \text {, enrolled (13, Li+; } 12 \text {, placebo),; } 21 \text {, } \\
\text { completed }\end{array}$ & $\begin{array}{l}\text { K-SADS, FH- } \\
\text { RDC; DSM- } \\
\text { III-R }\end{array}$ & $\begin{array}{l}\text { Lithium effectiveness: CGAS } \geq 65 \\
\text { [Response]; Li + serum level; Urine drug } \\
\text { essays; Lithium side effects (ALSES) }\end{array}$ \\
\hline [35] & RCT & USA & $\begin{array}{l}\mathrm{BD}(279, \text { manic or mixed } \\
\text { phase; mean age }=10.1)\end{array}$ & $\begin{array}{l}\text { 5671, screened; } 290 \text {, antimanic } \\
\text { medication naive randomly assigned to } \mathrm{Li} \\
+ \text { ( } 90, \text { completed), risperidone ( } 89, \\
\text { completed), DVPX ( } 100 \text { completed) }\end{array}$ & $\begin{array}{l}\text { WASH-U- } \\
\text { KSADS, } \\
\text { CGAS; DSM- } \\
\text { IV }\end{array}$ & $\begin{array}{l}\text { Lithium effectiveness: CGI-BP-IM } \leq 2 \text {, } \\
\text { KMRS [Response]; Lithium side effects }\end{array}$ \\
\hline [32] & $\begin{array}{l}\text { Prospective } \\
\text { non- } \\
\text { randomized } \\
\text { cohort }\end{array}$ & India & $\begin{array}{l}\mathrm{BD}(\mathrm{n}=25, \text { mania; mean } \\
\text { age }=14.1)\end{array}$ & $\begin{array}{l}\text { 26, enrolled; } 25 \text { completed a mean } \\
\text { duration of follow-up of } 51.6 \pm 4.1 \text { months }\end{array}$ & $\begin{array}{l}\text { DICA-R; } \\
\text { DSM-IV }\end{array}$ & $\begin{array}{l}\text { Lithium effectiveness: YMRS } \leq 12.5 \text {, } \\
\text { CGAS } \geq 51 \text { [Remission] }\end{array}$ \\
\hline$[24]$ & $\begin{array}{l}\text { Retrospective } \\
\text { cohort }\end{array}$ & USA & $\begin{array}{l}\mathrm{BD}(\mathrm{n}=48, \text { mania; mean } \\
\text { age }=15.7)\end{array}$ & $\begin{array}{l}48 \text {, treated ( } 25, \text { mania; } 23 \text { psychotic } \\
\text { mania) }\end{array}$ & $\begin{array}{l}\text { K-SADS-L, } \\
\text { YMRS > 16, } \\
\text { FH-RDC; } \\
\text { DSM-IV }\end{array}$ & $\begin{array}{l}\text { Lithium effectiveness: } \downarrow \text { YMRS }>33 \% \text {, } \\
\text { CGI } \leq 2 \text { [Response] }\end{array}$ \\
\hline$[17,18]$ & $\begin{array}{l}\text { Prospective } \\
\text { non- } \\
\text { randomized } \\
\text { cohort }\end{array}$ & USA & $\begin{array}{l}\mathrm{BD}(\mathrm{psychotic} \text { mania } \\
\mathrm{n}=28 ; \text { mean age }=15.9)\end{array}$ & $\begin{array}{l}\text { 35, enrolled; } 28 \text {, completed } 4 \text { weeks } \\
\text { ( } \mathrm{Li}+\text { and antipsychotic })(14, \\
\mathrm{Li}+\text { monotherapy) }\end{array}$ & $\begin{array}{l}\text { YMRS; DSM- } \\
\text { IV }\end{array}$ & $\begin{array}{l}\text { Lithium effectiveness: } \downarrow \text { YMRS }>33 \% \text {, } \\
\text { CGI } \leq 2 \text { [Response]; YMRS } \leq 6 \\
\text { [Remission] }\end{array}$ \\
\hline$[17,18]$ & $\begin{array}{l}\text { Prospective } \\
\text { non- } \\
\text { randomized } \\
\text { cohort }\end{array}$ & USA & $\begin{array}{l}\mathrm{BD}(\mathrm{n}=10: \text { psychotic } \\
\text { mania }=5, \text { nonpsychotic } \\
\text { mania }=5 ; \text { mean } \\
\text { age }=16.42)\end{array}$ & 10, treated $(5, \mathrm{Li}+$ and haloperidol; $5, \mathrm{Li}+)$ & $\begin{array}{l}\text { YMRS; DSM- } \\
\text { IV }\end{array}$ & $\begin{array}{l}\text { Lithium effectiveness: } \downarrow \text { YMRS }>33 \% \text {, } \\
\text { CGI } \leq 2 \text { [Response] }\end{array}$ \\
\hline [22] & $\begin{array}{l}\text { Prospective } \\
\text { non- } \\
\text { randomized } \\
\text { cohort }\end{array}$ & USA & $\begin{array}{l}\mathrm{BD}(\mathrm{n}=100, \text { acute } \\
\text { mania; mean age }=15.2)\end{array}$ & 100 , treated & $\begin{array}{l}\text { K-SADS-L; } \\
\text { DSM-IV }\end{array}$ & $\begin{array}{l}\text { Lithium effectiveness: } \downarrow \text { YMRS }>33 \% \text {, } \\
\text { CGI } \leq 2 \text { [Response]; YMRS } \leq 6 \\
\text { [Remission] }\end{array}$ \\
\hline [25] & $\mathrm{RCT}$ & USA & $\begin{array}{l}\mathrm{BD}(\mathrm{n}=100, \text { acute } \\
\text { mania; mean age }=15.2)\end{array}$ & $\begin{array}{l}\text { 100, enrolled; } 40 \text {, randomized ( } 19, \mathrm{Li}+; 21 \text {, } \\
\text { placebo) }\end{array}$ & $\begin{array}{l}\text { K-SADS-L; } \\
\text { DSM-IV }\end{array}$ & $\begin{array}{l}\text { Lithium effectiveness: } \downarrow \text { YMRS }>33 \% \text {, } \\
\text { CGI } \leq 2 \text { [Response]; YMRS } \leq 6 \\
\text { [Remission] }\end{array}$ \\
\hline [36] & RCT & USA & $\begin{array}{l}\mathrm{BD}(\mathrm{n}=42 \text {, acute phase, } \\
\text { manic or mixed; range } \\
\text { age }=6-18)\end{array}$ & $\begin{array}{l}\text { 42, treated (14, lithium; } 15, \text { DVPX; } 13 \text {, } \\
\text { CBZ) }\end{array}$ & $\begin{array}{l}\text { YMRS; DSM- } \\
\text { IV }\end{array}$ & $\begin{array}{l}\text { Lithium effectiveness: YMRS and CGI } \\
\downarrow \geq 50 \% \text { [Response] }\end{array}$ \\
\hline [39] & $\begin{array}{l}\text { Prospective } \\
\text { non- } \\
\text { randomized } \\
\text { cohort }\end{array}$ & USA & $\begin{array}{l}\mathrm{BD}(\mathrm{n}=35: \text { mania }=17 \\
\text { hypomania }=18 ; \text { mean } \\
\text { age }=11)\end{array}$ & $\begin{array}{l}\text { 42, enrolled; } 35 \text {, elected to continue ( } 18 \\
\text { acute-phase responders, } 17 \text { acute phase } \\
\text { non-responders) }\end{array}$ & $\begin{array}{l}\text { K-SADS; } \\
\text { DSM-IV }\end{array}$ & $\begin{array}{l}\text { Lithium effectiveness: CGI } \leq 2 \text {, } \\
\downarrow \text { YMRS } \geq 50 \% \text { [Response] }\end{array}$ \\
\hline [21] & $\mathrm{RCT}$ & USA & & & & \\
\hline
\end{tabular}


Table 1 (Continued)

\begin{tabular}{|c|c|c|c|c|c|c|}
\hline References & Study design & Country & Study population & $\mathrm{N}$ at entry/ Retained & $\begin{array}{l}\text { Diagnostic } \\
\text { assessment }\end{array}$ & Outcomes \\
\hline & & & $\begin{array}{l}\mathrm{BD}(\mathrm{n}=61, \text { manic or } \\
\text { mixed phase; mean } \\
\text { age }=13)\end{array}$ & $\begin{array}{l}\text { 61, enrolled; } 41 \text {, completed phase I; } 21 \text {, } \\
\text { completed phase II }\end{array}$ & $\begin{array}{l}\text { YMRS; DSM- } \\
\text { IV }\end{array}$ & $\begin{array}{l}\text { Lithium effectiveness: YMRS and CGI } \\
\downarrow \geq 50 \% \text { [Response] }\end{array}$ \\
\hline [33] & $\begin{array}{l}\text { Prospective } \\
\text { non- } \\
\text { randomized } \\
\text { cohort }\end{array}$ & USA & $\begin{array}{l}\text { Offsprings of manic- } \\
\text { depressive pts whose } \\
\text { parents were } \\
\mathrm{Li}+\text { responders }(\mathrm{n}=6 \text {; } \\
\text { mean age }=10.8)\end{array}$ & 6 , treated & $\begin{array}{l}\text { SADS, CPRS, } \\
\text { CARS; DSM- } \\
\text { III }\end{array}$ & $\begin{array}{l}\text { Lithium effectiveness (clinical criteria); } \\
\text { Average evoked potentials }\end{array}$ \\
\hline [44] & $\begin{array}{l}\text { Cross- } \\
\text { sectional }\end{array}$ & USA & $\begin{array}{l}\text { BD-I }(n=9 \text {, children, } \\
\text { mean age } 13.4 ; n=18, \\
\text { adults, mean age }=37.3)\end{array}$ & $\begin{array}{l}\text { 9, examined with In Vivo Magnetic } \\
\text { Resonance Spectroscopy }\end{array}$ & DSM-IV & Serum and brain $\mathrm{Li}+$ concentrations \\
\hline [28] & $\begin{array}{l}\text { Prospective } \\
\text { non- } \\
\text { randomized } \\
\text { cohort }\end{array}$ & USA & $\begin{array}{l}\mathrm{BD}-\mathrm{I}(\mathrm{n}=20 \text {, depression; } \\
\text { mean age }=15.6)\end{array}$ & $\begin{array}{l}53, \text { screened; } 27 \text {, enrolled; } 20, \text { completed } \\
\text { all } 6 \text { weeks }\end{array}$ & $\begin{array}{l}\text { WASH-U- } \\
\text { KSADS, } \\
\text { CDRS-R } \geq 40 \\
\text { Y-MRS } \leq 20 \\
\text { DSM-IV }\end{array}$ & $\begin{array}{l}\text { Lithium effectiveness: } \downarrow \text { CDRS-R } \geq 50 \% \\
\text { [Response]; CDRS-R } \leq 28 \text { and CGI-BD } \leq 2 \\
\text { [Remission] }\end{array}$ \\
\hline$[40]$ & $\begin{array}{l}\text { Prospective } \\
\text { non- } \\
\text { randomized } \\
\text { cohort }\end{array}$ & USA & $\begin{array}{l}\mathrm{BD}(\mathrm{n}=37 ; \text { mean } \\
\text { age }=12.1)\end{array}$ & $\begin{array}{l}40 \text {, enrolled; } 37 \text {, completed at least one } \\
\text { month (17, Li + and risperidone; } 20, \text { DVPX } \\
\text { and risperidone) }\end{array}$ & $\begin{array}{l}\text { YMRS, } \\
\text { WASH-U- } \\
\text { KSADS; } \\
\text { DSM-IV }\end{array}$ & $\begin{array}{l}\text { Lithium effectiveness: } \downarrow \text { YMRS } \geq 50 \% \\
\text { [Response]; } \downarrow \text { YMRS } \geq 50 \%, \text { CGI } \leq 2, \\
\text { CGAS } \geq 51 \text { [Remission] }\end{array}$ \\
\hline [37] & RCT & USA & $\begin{array}{l}\mathrm{BD}-\mathrm{I}(\mathrm{n}=210, \text { manic or } \\
\text { mixed phase; range } \\
\text { age }=6-15)\end{array}$ & $\begin{array}{l}\text { 279, enrolled; } 210 \text {, completed (61, Li+; } 74 \text {, } \\
\text { DVPX; } 75 \text {, risperidone) }\end{array}$ & $\begin{array}{l}\text { WASH-U- } \\
\text { KSADS; } \\
\text { DSM-IV }\end{array}$ & $\begin{array}{l}\text { Lithium effectiveness: CGI-BP-I-D } \leq 2 \text {, } \\
\text { CDRS-R } \leq 2 \text { [Response] }\end{array}$ \\
\hline [23] & $\begin{array}{l}\text { Prospective } \\
\text { non- } \\
\text { randomized } \\
\text { cohort }\end{array}$ & USA & $\begin{array}{l}\mathrm{BD}(\mathrm{n}=50 ; \text { range } \\
\text { age }=13-17)\end{array}$ & $\begin{array}{l}50 \text {, treated (15, prepubertal onset; } 35 \text {, } \\
\text { adolescent onset) }\end{array}$ & DSM-III & Lithium effectiveness: $\mathrm{CGI} \leq 2$ [Response] \\
\hline [30] & $\begin{array}{l}\text { Prospective } \\
\text { non- } \\
\text { randomized } \\
\text { cohort }\end{array}$ & USA & $\begin{array}{l}\text { BD-I }(n=24 ; \text { mean } \\
\text { age }=15.1)\end{array}$ & 37 , enrolled; 24 , completed & $\begin{array}{l}\text { RSMS;BHS; } \\
\text { DSM-III }\end{array}$ & $\begin{array}{l}\text { Lithium effectiveness: HAM-D } \leq 7 \\
\text { [Stable]; } \downarrow \text { BHS } \geq 50 \%, \downarrow \text { MSRS } \geq 50 \%, \text { CGI } \leq 2 \\
\text { for } 4 \text { weeks [Response] }\end{array}$ \\
\hline [27] & $\begin{array}{l}\text { Prospective } \\
\text { non- } \\
\text { randomized } \\
\text { cohort }\end{array}$ & USA & $\begin{array}{l}\text { BD-I }(n=60, \text { mania; } \\
\text { mean age }=15.2)\end{array}$ & $\begin{array}{l}60 \text {, treated ( } 30 \text { with, and } 30 \text { without a } \\
\text { prior history of early childhood ADHD) }\end{array}$ & $\begin{array}{l}\text { DSM-III-R or } \\
\text { DSM-IV }\end{array}$ & $\begin{array}{l}\text { Lithium effectiveness: CGI } \leq 2 \text { or } \\
\text { BMRS } \geq 50 \text { [Response] }\end{array}$ \\
\hline [26] & $\mathrm{RCT}$ & USA & $\begin{array}{l}\text { BD-I }(n=279 ; \text { mean } \\
\text { age }=10.1)\end{array}$ & $\begin{array}{l}\text { 279, enrolled (90, Li+; DVPX, 100; 89, } \\
\text { risperidone) }\end{array}$ & $\begin{array}{l}\text { WASH-U- } \\
\text { KSADS; } \\
\text { DSM-IV } \\
\text { DSM-IV }\end{array}$ & $\begin{array}{l}\text { Lithium effectiveness: CGI-BP-IM } \leq 2 \\
\text { [Response] }\end{array}$ \\
\hline [38] & $\mathrm{RCT}$ & USA & $\begin{array}{l}\text { BD-I }(n=99, \text { manic or } \\
\text { mixed phase; range } \\
\text { age }=6-15)\end{array}$ & $\begin{array}{l}\text { 154, enrolled; } 99 \text {, completed (42, Li+; } 27 \text {, } \\
\text { DVPX; 30, risperidone) }\end{array}$ & $\begin{array}{l}\text { WASH-U- } \\
\text { KSADS; } \\
\text { DSM-IV }\end{array}$ & $\begin{array}{l}\text { Lithium effectiveness: CGI-BP-IM } \leq 2 \text {, } \\
\text { KMRS } \leq 11 \text { [Response] }\end{array}$ \\
\hline
\end{tabular}

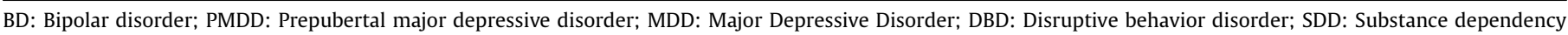

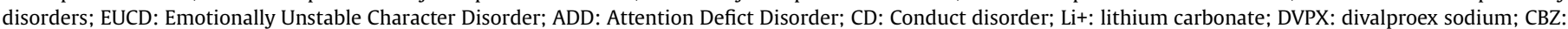

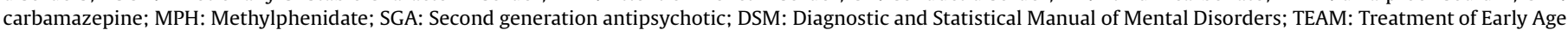

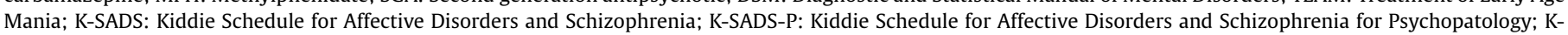

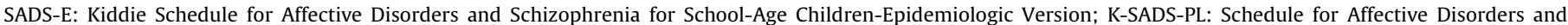

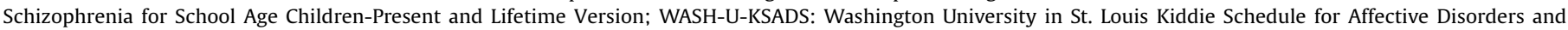

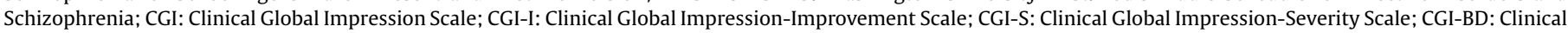



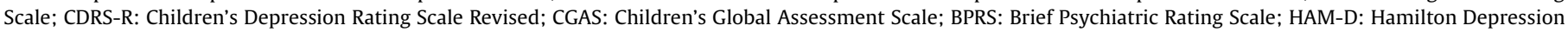

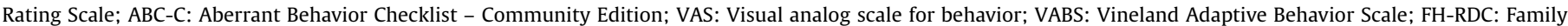



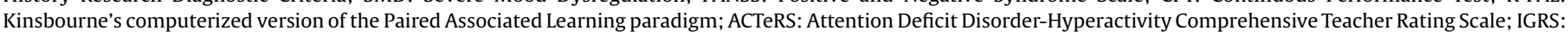

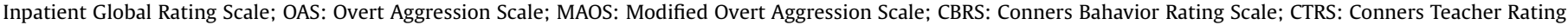



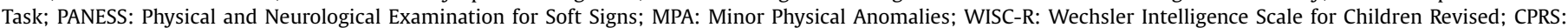

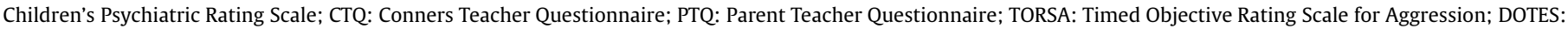

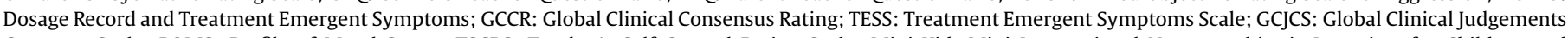

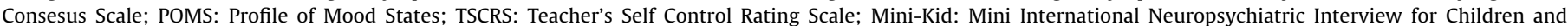

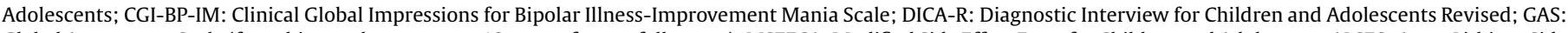



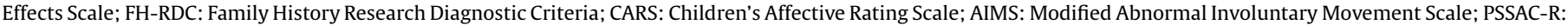

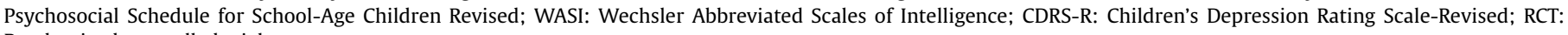
Randomized controlled trial. 
Table 2

Efficacy results and side effects of selected studies.

\begin{tabular}{|c|c|c|c|c|c|c|}
\hline References & Study design & $\begin{array}{l}\text { Sample } \\
\text { size }\end{array}$ & $\begin{array}{l}\text { Target serum level/ Dose/ Mean } \\
\text { Serum Level Achieved/ Mean } \\
\text { medication duration }\end{array}$ & $\begin{array}{l}\text { Concurrent } \\
\text { medications }\end{array}$ & Efficacy results & Side effects* \\
\hline
\end{tabular}

Lithium monotherapy

Manic or mixed episodes

[14] RCT

Mean serum level achieved, $1.05 \quad$ None $\mathrm{mEq} / \mathrm{L}$ (at the end of the study); ARM I, $1.15 \mathrm{mEq} / \mathrm{L}$; ARM II, $0.96 \mathrm{mEq} / \mathrm{L}$; ARM III, $1.05 \mathrm{mEq} / \mathrm{L}$

\begin{tabular}{|c|c|c|c|c|}
\hline [20] & RCT & 58 & $\begin{array}{l}\text { Mean dose, } 1292 \pm 420 \mathrm{mg} / \text { day (age } \\
7-11), 1716 \pm 606 \mathrm{mg} / \text { day }(12-17) ; \\
\text { Mean serum level achieved, } \\
0.98 \pm 0.47 \mathrm{mEq} / \mathrm{L}\end{array}$ & None \\
\hline [25] & RCT & 100 & $\begin{array}{l}\text { Target serum level, } 0.6-1.2 \mathrm{mEq} / \mathrm{L} \text {; } \\
\text { Serum level achieved, } 0.99 \pm 0.21 \text { (at } \\
\text { randomization) }\end{array}$ & $\mathrm{AP}, \mathrm{BDZ}$ \\
\hline [21] & RCT & 61 & $\begin{array}{l}\text { Mean serum level achieved, 0.8-1.2 } \\
\text { mEq/L (Maximum trough } \\
\text { concentration, } 1.4 \mathrm{mEq} / \mathrm{L} \text { ) }\end{array}$ & None \\
\hline
\end{tabular}

[26] RCT

Mean serum level achieved, 1.09 mEq/L; DVPX: Mean serum level achieved: $113.6 \mathrm{ug} / \mathrm{L}$; Risperidone: Mean dose: $2.57 \mathrm{mg} /$ day

NS

Mean dose, $1560 \mathrm{mg} /$ day; Man
serum level achieved, $0.93 \mathrm{mEq} / \mathrm{L}$

randomized cohort
Haloperidol

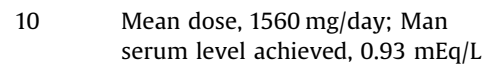

\begin{tabular}{|c|c|c|c|c|}
\hline$[22]$ & $\begin{array}{l}\text { Prospective } \\
\text { non- } \\
\text { randomized } \\
\text { cohort }\end{array}$ & 100 & $\begin{array}{l}\text { Target serum level, } 0.6-1.2 \mathrm{mEq} / \mathrm{L} \text {; } \\
\text { Dose, } 1355 \pm 389 \mathrm{mg} / \mathrm{day} ; \text { Serum } \\
\text { level achieved, } 0.93 \pm 0.21 \mathrm{mEq} / \mathrm{L}\end{array}$ & $\mathrm{AP}, \mathrm{BDZ}$ \\
\hline [23] & $\begin{array}{l}\text { Prospective } \\
\text { non- } \\
\text { randomized } \\
\text { cohort }\end{array}$ & 50 & Target, $0.9-1.5 \mathrm{mEq} / \mathrm{L}$ & $\mathrm{AP}$ \\
\hline [27] & $\begin{array}{l}\text { Prospective } \\
\text { non- } \\
\text { randomized } \\
\text { cohort }\end{array}$ & 60 & $\begin{array}{l}\text { Target serum level, } 0.9-1.5 \mathrm{mEq} / \mathrm{L} \text {; } \\
\text { Mean serum level achieved, } 1.12 \\
\mathrm{mEq} / \mathrm{L}\end{array}$ & AP \\
\hline
\end{tabular}

Of the 61 youths [32 males (52.5\%)] Vomiting, headhache, who received open-label lithium, 60 abdominal pain, tremor, $\uparrow$ TSH youths completed at least 1 week of treatment and returned for a postbaseline assessment; most pts had an improvement in YMRS of $50 \%$, and more than half of the pts (58\%) achieved response; all 3 treatment arms had similar effectiveness, tolerability, side effect profile.

YMRS score larger in Li+-treated Thyrotropin concentration participants (5.51[95\% CI:0.5110.50]) after adjustment for baseline $(3.0 \pm 3.1 \mathrm{mIU} / \mathrm{L})$ compared YMRS score, age group, weight group, gender, and study site. CGI-I L). scores favored $\mathrm{Li}+(47 \%)$ compared with placebo (21\%) at week 8/ET. Response rates: $20 \%$ in pts with psychotic or aggressive symptoms, $60.3 \%$ in pts without. No significant differences in exacerbation rate ( $\mathrm{Li}+$ $52.6 \%$ vs. placebo, $61.9 \%$ )

A daily lithium carbonate dose of $25 \mathrm{mg} / \mathrm{kg}$ total body weight (rounded to 300-mg capsules) in two doses/day was predicted to achieve $a \geq 50 \%$ Young Mania Rating Scale reduction in $74 \%$ of patients, with approximately $8 \%$ of patients expected to have trough concentrations above the nominal safety threshold of $1.4 \mathrm{mEq} / \mathrm{L}$. RR for risperidone vs. $\mathrm{Li}+$ ranged NS from $1.2(95 \% \mathrm{CI} 0.8,1.7)$ to $8.3(1.1$, $60.8)$, and for risperidone vs. DVPX from $1.3(0.8,2.2)$ to $10.5(1.4,77.7)$; RR for risperidone vs. $\mathrm{Li}+$ was 2.1 for patients with ADHD, but 1.0 for those without ADHD, and 2.3 (1.6, 3.3) for non-obese patients, but 1.1 $(0.6,2.0)$ for obese ones

Under haloperidol treatment, all pts NS had full resolution of psychotic features and significant declines across all measures at the end of week-1. However, within 1 week of haloperidol discontinuation (mean $=4.7$ days, range 17 days), all pts had clinically significant return of their psychosis and/or agitation despite ongoing treatment with $\mathrm{Li}+$ ( mean dose $=1560 \mathrm{mg} /$ day; mean $\mathrm{Li}+$ level $=0.93 \mathrm{mEq} / \mathrm{L}$ ). In contrast to the group with psychosis where none of pts was rated as a responder, $60 \%$ of non psychotic pts were responders to 4 weeks of

$\mathrm{Li}+$ monotherapy.

Response rates: 63\%; Effect size: 1.48, YMRS; 1.21 , CGAS; $1.40, \mathrm{GCI}$; $26 \%$ pts achieved remisison of manic symptoms; $83 \%$ pts showed reduction in suicidality. Response rate (at 6 weeks): $68 \%$ (80\% Rash, tremor adolescent onset; $40 \%$ prepubertal onset)

Polydipsia, $\uparrow$ weight or appetite (> 10\% Pt. at week-4)

BRMS scores decreased by a mean of Rash, tremor 24.3 in the subgroup without prior ADHD compared to 16.7 in pts with ADHD. The average percent drop in 
Table 2 (Continued)

\begin{tabular}{|c|c|c|c|c|c|c|}
\hline References & Study design & $\begin{array}{l}\text { Sample } \\
\text { size }\end{array}$ & $\begin{array}{l}\text { Target serum level/ Dose/ Mean } \\
\text { Serum Level Achieved/ Mean } \\
\text { medication duration }\end{array}$ & $\begin{array}{l}\text { Concurrent } \\
\text { medications }\end{array}$ & Efficacy results & Side effects* \\
\hline [24] & $\begin{array}{l}\text { Retrospective } \\
\text { cohort }\end{array}$ & 48 & NS & Haloperidol & $\begin{array}{l}\text { BRMS scores over the study period in } \\
\text { these two subgroups was } 80.6 \% \text { and } \\
57.7 \% \text {, respectively. Median time to } \\
\text { onset of sustained improvement was } \\
\text { lengthened significantly in patients } \\
\text { with early ADHD ( } 23 \text { days) } \\
\text { compared to those without it ( } 17 \\
\left.\text { days; log rank } \chi^{2}=57.2\right) \text {. } \\
\text { Response rate: } 53.5 \%(23 / 43 \text { ) ( } 70.8 \% \text {, } \\
\text { non-psychotic and } 31.6 \% \text {, psychotic). } \\
\text { Subjects without a childhood } \\
\text { psychiatric diagnosis declined from } \\
\text { a mean of } 30.25 \text { (SD }=9.31 \text { ) at } \\
\text { baseline to } 9.96(S D=8.00) \text { at the } \\
\text { end of treatment; subjects with a } \\
\text { childhood diagnosis of ADHD had a } \\
\text { mean initial score of } 27.72 \\
\text { (SD } 6.98) \text { at baseline and a mean } \\
\text { score of } 14.78 \text { (SD }=8.98) \text { at the end } \\
\text { of the protocol; decline in mean } \\
\text { scores across both groups was } \\
\text { statistically significant }(F=41.40 \text {, } \\
d f=1.19 \text { ). }\end{array}$ & NS \\
\hline \multicolumn{7}{|c|}{ Depressive episodes } \\
\hline [28] & $\begin{array}{l}\text { Prospective } \\
\text { non- } \\
\text { randomized } \\
\text { cohort }\end{array}$ & 20 & $\begin{array}{l}\text { Dose adjusted to obtain serum level } \\
\text { of } 1-1.2 \mathrm{mEq} / \mathrm{L}\end{array}$ & None & $\begin{array}{l}\text { Mean CDRS-R scores decreased from } \\
\text { baseline to endpoint (mean [SD] } \\
\text { change }=-25.5, S D=20.4 \text { ), effect } \\
\text { size }=1.7 . \text { Response and remission } \\
\text { rates, } 48 \% \text { and } 30 \% \text {. }\end{array}$ & $\begin{array}{l}\text { Headhache, nausea, vomiting, } \\
\text { stomachache, abdominal } \\
\text { cramps }\end{array}$ \\
\hline $\begin{array}{l}\text { Prophylaxis } \\
{[15,16]}\end{array}$ & $\mathrm{RCT}$ & 25 & $\begin{array}{l}\text { Target serum level, } 0.9-1.3 \mathrm{mEq} / \mathrm{L} \text {; } \\
\text { Dose, } 1769 \pm 401 \mathrm{mg} / \mathrm{d} \text {; Serum level } \\
\text { achieved, } 0.98 \pm 0.33 \mathrm{mEq} / \mathrm{L}\end{array}$ & NS & $\begin{array}{l}\text { Intent-to-treat response: } 46.2 \% \text {, } \\
\mathrm{Li}+\mathrm{vs} 8.3 \% \text {, placebo; completer } \\
\text { group response: } 60 \%, \mathrm{Li}+\mathrm{vs} 9.1 \% \text {, } \\
\text { placebo; no differences between } \\
\text { groups for mood or SDD symptoms. }\end{array}$ & Polydypsia, polyuria \\
\hline [29] & $\begin{array}{l}\text { Prospective } \\
\text { non- } \\
\text { randomized } \\
\text { cohort }\end{array}$ & 59 & $\begin{array}{l}\text { Dose, } 400-1200 \mathrm{mg} / \mathrm{day} ; \text { Serum } \\
\text { levels, } 0.5-1.2 \mathrm{mEq} / \mathrm{L}\end{array}$ & NS & $\begin{array}{l}\text { Diagnosis successfully treated: } \\
\text { manic-depression (66\%), depression } \\
\text { (17\%) ADD 0\%, EUCD (82\%), CD (15\%), } \\
\text { ADD affective (38\%), affective/ } \\
\text { aggressive/explosive (56\%), } \\
\text { developmental disorder (29\%), } \\
\text { offspring of Li + responder ( } 71 \%) \text {. }\end{array}$ & $\begin{array}{l}\text { Thyroid enlargement without } \\
\text { hypothyroidism ( } 1 \mathrm{Pt} .)\end{array}$ \\
\hline [31] & $\begin{array}{l}\text { Prospective } \\
\text { non- } \\
\text { randomized } \\
\text { cohort }\end{array}$ & 41 & $\begin{array}{l}\text { Dose, } 27.8 \mathrm{mg} / \mathrm{kg} / \text { day (at the and of } \\
\text { Phase-2); Mean serum level } \\
\text { achieved, } 1.0 \mathrm{mEq} / \mathrm{L}\end{array}$ & $\begin{array}{l}\text { DVPX, MPH, } \\
\text { risperidone }\end{array}$ & $\begin{array}{l}41 \text { pts received continued open-label } \\
\text { long-term treatment with lithium } \\
\text { for a mean of } 14.9(3.0) \text { weeks during } \\
\text { Phase II; the mean weight-adjusted } \\
\text { total daily dose at end of Phase II was } \\
27.8(6.7) \mathrm{mg} / \mathrm{kg} / \mathrm{day} \text {, with an } \\
\text { average lithium concentration of } 1.0 \\
(0.3) \mathrm{mEq} / \mathrm{L} ; 60.9 \% \text { Pt. ( } 26 / 41) \text { were } \\
\text { prescribed adjunctive psychotropic } \\
\text { medications for residual symptoms; } \\
\text { the most frequent indications for } \\
\text { adjunctive medications were } \\
\text { refractory mania ( } \mathrm{n}=13 ; 31.7 \%) \text { and } \\
\text { ADHD ( } \mathrm{n}=15 ; 36.6 \%) ; \text { at the end of } \\
\text { this phase } 28(68.3 \%) \text { pts met a priori } \\
\text { criteria for response, with } 22(53.7 \%) \\
\text { considered to be in remission. }\end{array}$ & $\begin{array}{l}\text { Vomiting, headhache, } \\
\text { abdominal pain, tremor }\end{array}$ \\
\hline [32] & $\begin{array}{l}\text { Prospective } \\
\text { non- } \\
\text { randomized } \\
\text { cohort }\end{array}$ & 25 & $\begin{array}{l}\text { Mean dose, } 1074 \mathrm{mg} \text {; Serum level } \\
\text { achieved, } 0.8-1.2 \mathrm{mEq} / \mathrm{L}\end{array}$ & $\begin{array}{l}\text { Clorpromazine, } \\
\text { haloperidol, } \\
\text { risperidone, } \\
\text { CBZ, DVPX, } \\
\text { imipramine }\end{array}$ & $\begin{array}{l}64 \%(16 / 25) \text { of pts relapsed after a } \\
\text { mean period of } 18 \pm 16.4 \text { months; } \\
72.4 \% \text { of the relapses were while the } \\
\text { subjects were on treatment and the } \\
\text { majority of them }(87 \%, 20 / 23) \\
\text { occurred while the pts were on } \\
\text { lithium (alone or in combination). }\end{array}$ & NS \\
\hline [30] & $\begin{array}{l}\text { Prospective } \\
\text { non- } \\
\text { randomized } \\
\text { cohort }\end{array}$ & 24 & $\begin{array}{l}\text { Target serum level, } 0.6-1.2 \mathrm{mEq} / \mathrm{L} \text {; } \\
\text { Serum level achieved, } 0.7-1.4 \mathrm{mEq} / \mathrm{L} \\
\text { (at stabilization), } 0.79 \mathrm{mEq} / \mathrm{L} \text { (at end } \\
\text { of } 18 \text { month) }\end{array}$ & $\mathrm{AP}, \mathrm{CBZ}$ & $\begin{array}{l}56.8 \%(21 / 37) \text { pts relapsed; relapse } \\
\text { rate higher in non completers } \\
\text { ( } 92.3 \%) \text { than in completers ( } 37.5 \%) \text {. } \\
\text { Completers who had had previous } \\
\text { episodes showed a decline in the } \\
\text { mean } \pm S D \text { number of episodes } \\
\text { during the follow-up }(1.70, S D=0.78 \\
\text { vs. } 0.8, S D=1.00) \text {. }\end{array}$ & NS \\
\hline
\end{tabular}


Table 2 (Continued)

\begin{tabular}{|c|c|c|c|c|c|c|}
\hline References & Study design & $\begin{array}{l}\text { Sample } \\
\text { size }\end{array}$ & $\begin{array}{l}\text { Target serum level/ Dose/ Mean } \\
\text { Serum Level Achieved/ Mean } \\
\text { medication duration }\end{array}$ & $\begin{array}{l}\text { Concurrent } \\
\text { medications }\end{array}$ & Efficacy results & Side effects* \\
\hline [33] & $\begin{array}{l}\text { Prospective } \\
\text { non- } \\
\text { randomized } \\
\text { cohort }\end{array}$ & 6 & Serum level achieved, $0.8-1.2 \mathrm{mEq} / \mathrm{L}$ & None & $\begin{array}{l}\text { Response rates: } 33 \%(2 / 6) \text {; these pts } \\
\text { were strong augmenters on the EP. }\end{array}$ & NS \\
\hline \multicolumn{7}{|c|}{ Lithium monotherapy vs. other psychotropic drugs } \\
\hline$[34]$ & RCT & 60 & $\begin{array}{l}\text { Target serum level, } 0.6-1.2 \mathrm{mEq} / \mathrm{L} \text {; } \\
\text { Dose, } 30 \mathrm{mg} / \mathrm{kg} / \mathrm{d} ; \text { Serum level } \\
\text { achieved, } 94 \pm 0.26 \mathrm{mEq} / \mathrm{L} ; \text { DVPX: } \\
\text { Target serum level, } 50-100 \mu \mathrm{g} / \mathrm{mL} \text {; } \\
\text { Dose, } 20 \mathrm{mg} / \mathrm{kg} / \mathrm{d} \text {; Serum level } \\
\text { achieved, } 81.1 \pm 20.5 \mu \mathrm{g} / \mathrm{mL}\end{array}$ & Stimulants & $\begin{array}{l}63.5 \% \text { of youths exited the study for } \\
\text { mood-related reasons ( } 60 \%, \mathrm{Li}+; \\
66.7 \% \text {, DVPX); time to mood relapse } \\
\text { did not differ between the Li and } \\
\text { DVPX treatment groups (log-rank [ } 1 \\
\text { df] }=0.35 \text { ); the two treatment } \\
\text { groups did not differ in time until } \\
\text { study discontinuation for any reason } \\
\text { (log-rank [ } 1 \mathrm{df} \text { ] } 0.13 \text { ); youths with a } \\
\text { younger age of onset were more } \\
\text { likely to relapse; youths with higher } \\
\text { YMRS scores at baseline were more } \\
\text { likely to discontinue study early. }\end{array}$ & $\begin{array}{l}\text { Emesis, enuresis, headache, } \\
\text { stomach pain }\end{array}$ \\
\hline [35] & $\mathrm{RCT}$ & 279 & $\begin{array}{l}\text { Mean serum level achieved, } \\
1.09 \mathrm{mmol} / \mathrm{L} \text {; Dose } 872 \mathrm{mg} / \mathrm{day} ; \\
\text { DVPX: Mean serum level achieved, } \\
113.6 \mathrm{ug} / \mathrm{mL} \text {; Rsperidone: Mean } \\
\text { dose, } 2.57 \mathrm{mg}\end{array}$ & $\mathrm{MPH}$ & $\begin{array}{l}\text { Higher response rates occurred with } \\
\text { risperidone vs } \mathrm{Li}+(68.5 \% \text { vs } 35.6 \% \\
\left.\chi^{2}=16.9\right) \text { and vs DVPX ( } 68.5 \% \text { vs } \\
\left.24.0 \% ; \chi^{2}=28.3\right) . \text { Response to } \mathrm{Li}+\mathrm{vs} \\
\text { DVPX did not differ; the } \\
\text { discontinuation rate was higher for } \\
\mathrm{Li}+\text { than for risperidone }\left(\chi^{2}=6.4\right) \text {. }\end{array}$ & $\begin{array}{l}\text { Abdominal pain, weight gain/ } \\
\text { loss, headache, dry mounth, } \\
\text { nasal congestion, frequent } \\
\text { urination, excessive thirst, } \\
\uparrow \mathrm{TSH}\end{array}$ \\
\hline [36] & $\mathrm{RCT}$ & 42 & $\begin{array}{l}\text { Target serum level, 0.8-1.2 mEq/L; } \\
\text { Dose, } 30 \mathrm{mg} / \mathrm{kg} / \mathrm{day} \text {; Serum level } \\
\text { achieved, } 0.88 \pm 0.35 \mathrm{mEq} / \mathrm{L} ; \mathrm{DPVX} \text { : } \\
\text { Target serum level, } 85-10 \mu \mathrm{g} / \mathrm{mL} \text {; } \\
\text { Dose, } 20 \mathrm{mg} / \mathrm{kg} / \mathrm{day} \text {; Serum level } \\
\text { achieved, } 82.8 \pm 22.92 \mu \mathrm{g} / \mathrm{mL} ; \mathrm{CBZ:} \\
\text { Target serum level, } 7-10 \mu \mathrm{g} / \mathrm{L} \text {; Dose, } \\
15 \mathrm{mg} / \mathrm{kg} / \mathrm{day} \text {; Serum level achieved, } \\
7.11 \pm 1.79 \mu \mathrm{g} / \mathrm{L}\end{array}$ & Chlorpromazine & $\begin{array}{l}\text { Effect size: } 1.63, \text { DVPX; } 1.06, \mathrm{Li}+ \\
\text { 1.00, CBZ. Response rates: } 53 \% \\
\text { DVPX; } 38 \%, \mathrm{Li}+; 38 \%, \mathrm{CBZ}\left(\chi^{2}=0.85\right)\end{array}$ & Nausea, $\uparrow$ appetite \\
\hline [37] & RCT & 210 & $\begin{array}{l}\text { Mean serum level achieved, } 1.09 \\
\text { mEq/L; DVPX: Mean serum level } \\
\text { achieved: } 113.6 \mathrm{ug} / \mathrm{L} \text {; Risperidone: } \\
\text { Mean dose: } 2.57 \mathrm{mg} / \text { day. }\end{array}$ & $\begin{array}{l}\text { DVPX, } \\
\text { risperidone }\end{array}$ & $\begin{array}{l}\text { CGI-BP-I-D ratings better in the } \\
\text { risperidone group }(60.7 \%) \text { as } \\
\text { compared to the } \mathrm{Li}+(42.2 \%) \text { or DPVX } \\
\text { ( } 35.0 \% \text { ) groups from baseline to the } \\
\text { end of the study. CDRS scores in all } \\
\text { treatment groups improved equally } \\
\text { by study end. In week } 1 \text {, scores were } \\
\text { lower with risperidone compared to } \\
\text { DPVX (mean }=4.72,95 \% \mathrm{CI}=2.67 \text {, } \\
6.78) \text {, and compared to } \mathrm{Li}+ \\
\text { (mean }=3.63,95 \% \mathrm{CI}=1.51,5.74) \text {, } \\
\text { although group differences were not } \\
\text { present by the end of the study. No } \\
\text { overall effect of treatment on } \\
\text { suicidality ratings. }\end{array}$ & NS \\
\hline [38] & RCT & 99 & $\begin{array}{l}\text { Endpoint blood levels or dose in the } \\
\text { complete sample of treatment-naive } \\
\text { participants: } \mathrm{Li}+0.75 \pm 0.4 \mathrm{mEq} / \mathrm{mL} \text {; } \\
\text { DPVX } 85.5 \pm 36.3 \mathrm{mg} / \mathrm{mL} \text {; and } \\
\text { risperidone } 2.3 \pm 1.2 \mathrm{mg} \text { daily. } \\
\text { Among treatment-naive responders: } \\
\mathrm{Li}+0.89 \pm 0.3 \mathrm{mEq} / \mathrm{L} \text {; DPVX, } \\
88.7 \pm 45.2 \mathrm{mg} / \mathrm{mL} \text {; risperidone was } \\
2.3 \pm 1.2 \mathrm{mg} \text { daily. Among partial } \\
\text { responders who received add-on } \\
\text { treatment: } \mathrm{Li}+0.70 \pm 0.5 \mathrm{mEq} / \mathrm{L} \text {; } \\
\text { DPVX, } 61 \pm 37.5 \mathrm{mg} / \mathrm{mL} \text {; risperidone } \\
\text { was } 2.1 \pm 1.7 \mathrm{mg} \mathrm{daily.} \mathrm{Among} \mathrm{non-} \\
\text { responders: } \mathrm{Li}+, 1.09 \pm 0.3 \mathrm{mEq} / \mathrm{L} \text {; } \\
\text { DPVX, } 114 \pm 23 \mathrm{mg} / \mathrm{mL} \text {; risperidone, } \\
2.6 \pm 1.2 \mathrm{mg} \text {. }\end{array}$ & $\begin{array}{l}\text { DVPX, } \\
\text { risperidone }\end{array}$ & $\begin{array}{l}\text { Response rate for children switched } \\
\text { to risperidone }(47.6 \%) \text { was higher } \\
\text { than for those switched to either } \mathrm{Li}+ \\
(12.8 \% \text {; NT }=3 ; 95 \% \mathrm{CI}=1.71-9.09) \\
\text { or DVPX }(17.2 \% \text {; NNT }=3 ; 95 \% \\
\mathrm{CI}=1.79-20.10) \text {. Response rate for } \\
\text { partial responders who added } \\
\text { risperidone (53.3\%) was higher than } \\
\text { for those who added divalproex (0\%; } \\
\mathrm{NNT}=2 ; 95 \% \mathrm{CI}=1.27-3.56) \text { and } \\
\text { trended higher for lithium }(26.7 \% \text {; } \\
\text { NNT }=4) \text {. }\end{array}$ & $\begin{array}{l}\text { Weight gain }(\mathrm{kg}) \text { was observed } \\
\text { for all add-on medications: } \\
\mathrm{Li}+\text { add-on }=1.66 \pm 1.97 ; \\
\text { risperidone add- } \\
\text { on }=2.8 \pm 1.34 ; \text { DPVX add- } \\
\text { on }=1.42 \pm 1.96\end{array}$ \\
\hline
\end{tabular}

Lithium in combination with adjunctive agents

[17,18] Prospective non- $28 \quad$ Target serum level, 0.6-1.2 mEq/L; BDZ

randomized

Mean serum level achieved, 0.88

cohort

$\mathrm{mEq} / \mathrm{L}$; Haloperidol: Dose, 5-10 mg

day; Risperidon: Dose, $\leq 6 \mathrm{mg} /$ day

Response rate to combination treatment: $64.3 \%$; $57 \%(8 / 14)$ stable on monotherapy for 4 weeks. Succesfull discontinuation of antipsychotic is associated with first episode, shorter duration of psychosis, presence of thought disorder at baseline.
71\% minimal, $22.9 \%$ moderate functional impairment (mainly GI symptoms) 
Table 2 (Continued)

\begin{tabular}{|c|c|c|c|c|c|c|}
\hline References & Study design & $\begin{array}{l}\text { Sample } \\
\text { size }\end{array}$ & $\begin{array}{l}\text { Target serum level/ Dose/ Mean } \\
\text { Serum Level Achieved/ Mean } \\
\text { medication duration }\end{array}$ & $\begin{array}{l}\text { Concurrent } \\
\text { medications }\end{array}$ & Efficacy results & Side effects* \\
\hline [39] & $\begin{array}{l}\text { Prospective non- } \\
\text { randomized } \\
\text { cohort }\end{array}$ & 35 & $\begin{array}{l}\text { Target serum level, 0.8-1.2 mEq/L; } \\
\text { Dose, } 30 \mathrm{mg} / \mathrm{kg} / \mathrm{d} \text {; Serum level } \\
\text { achieved, } 0.88 \pm 0.35 \mathrm{mEq} / \mathrm{L} ; \mathrm{DPVX} \text { : } \\
\text { Target serum level, } 85-110 \mu \mathrm{g} / \mathrm{ml} \text {; } \\
\text { Dose, } 20 \mathrm{mg} / \mathrm{kg} / \mathrm{d} \text {; Serum level } \\
\text { achieved, } 82.8 \pm 22.92 \mu \mathrm{g} / \mathrm{ml} \\
\text { CBZ: target, } 7-10 \mu \mathrm{g} / \mathrm{L} ; \text { dose, } 15 \mathrm{mg} / \\
\mathrm{kg} / \mathrm{d} \text {; achieved, } 7.11 \pm 1.79 \mu \mathrm{g} / \mathrm{L}\end{array}$ & $\begin{array}{l}\text { MS, AD, AP, } \\
\text { Stimulants }\end{array}$ & $\begin{array}{l}58 \%(20 / 35) \text { of pts required } \\
\text { treatment with one or two mood } \\
\text { stabilizers and either a stimulant, an } \\
\text { atypical antipsychotic agent, or an } \\
\text { antidepressant agent. Response rate } \\
\text { to combination therapy: } 80 \% \text { of } \\
\text { subjects treated responding to } \\
\text { combination therapy with two mood } \\
\text { stabilizers after not responding to } \\
\text { monotherapy with a mood stabilizer. }\end{array}$ & Nausea, $\uparrow$ appetite \\
\hline$[40]$ & $\begin{array}{l}\text { Prospective non- } \\
\text { randomized } \\
\text { cohort }\end{array}$ & 37 & $\begin{array}{l}\text { Target serum level, } 0.6-1.0 \mathrm{mEq} / \mathrm{L} \text {; } \\
\text { Dose, } 10-30 \mathrm{mg} / \mathrm{kg} / \mathrm{day} \\
(750 \pm 400 \mathrm{mg} / \mathrm{day}) ; \text { Mean serum } \\
\text { level achieved, } 0.9 \mathrm{mEq} / \mathrm{L} ; \\
\text { Risperidon: Target serum level, } \\
0.25-0.50 \mathrm{mg} / \text { day to max } 3 \mathrm{mg} / \mathrm{day} \text {; } \\
\text { DPVX: Target serum level, } 50- \\
120 \mu \mathrm{g} / \mathrm{mL} ; \text { Dose, } 15-20 \mathrm{mg} / \mathrm{kg} / \mathrm{day} \\
(925 \pm 325 \mathrm{mg} / \mathrm{day}) ; \mathrm{Mean} \text { serum } \\
\text { level achieved, } 106 \mu \mathrm{g} / \mathrm{mL}\end{array}$ & $\begin{array}{l}\text { Stimulants, } \\
\text { Clonidine, } \\
\text { Benzotropines, } \\
\text { Trazodone }\end{array}$ & $\begin{array}{l}\text { Effect sizes (Cohen's d) based on } \\
\text { change of YMRS scores from baseline } \\
\text { were } 4.36 \text { for DVPX-risperidone and } \\
2.82 \text { for Li+-risperidone. Response } \\
\text { rates: } 80 \% \text { for DVPX + Risp and } 82.4 \% \\
\text { for Li+-risperidone. }\end{array}$ & Weight gain, sedation, nausea \\
\hline [19] & $\begin{array}{l}\text { Prospective non- } \\
\text { randomized } \\
\text { cohort }\end{array}$ & 107 & Mean serum levels, $0.6-1.2 \mathrm{mmol} / \mathrm{L}$ & None & $\begin{array}{l}\text { Maternal }(\mathrm{r}=-0.31) \text { and paternal }(\mathrm{r}= \\
-0.44) \text { hospitalization for a } \\
\text { psychiatric disorder and less } \\
\text { adaptive family functioning }(\mathrm{r}= \\
-0.26) \text { related to treatment } \\
\text { nonadherence for DVPX. Better } \\
\text { treatment adherence to DVPX } \\
(\mathrm{r}=0.21) \text { and } \mathrm{L}+(\mathrm{r}=0.23) \text { was } \\
\text { associated with a greater number of } \\
\text { side effects, whereas male sex was } \\
\text { associated with worse adherence to } \\
\text { both DVPX ( } \mathrm{r}=-0.24) \text { and Li+ }(\mathrm{r}= \\
-0.22) \text { pharmacotherapy. Clinical } \\
\text { response to treatment correlated } \\
\text { with adherence to DVPX treatment } \\
\text { ( } \mathrm{r}=0.33 \text { ). }\end{array}$ & NS \\
\hline [41] & $\begin{array}{l}\text { Prospective non- } \\
\text { randomized } \\
\text { cohort }\end{array}$ & 90 & $\begin{array}{l}\text { Target serum level, 0.6-1.2 mEq/L; } \\
\text { Dose, } 30 \mathrm{mg} / \mathrm{kg} / \mathrm{day} \\
(923.3 \pm 380.2 \mathrm{mg} / \mathrm{day}) ; \text { Serum level } \\
\text { achieved, } 0.9 \pm 0.3 \mathrm{mEq} / \mathrm{L} ; \text { DVPX: } \\
\text { Target serum level, } 50-100 \mu \mathrm{gg} / \mathrm{ml} \text {; } \\
\text { Dose, } 20 \mathrm{mg} / \mathrm{kg} / \text { day } \\
\text { ( } 862.5 \pm 397.5 \mathrm{mg} / \text { day); Serum level } \\
\text { achieved, } 79.8 \pm 25.9 \mu \mathrm{g} / \mathrm{ml}\end{array}$ & $\begin{array}{l}\text { Stimulants, AP, } \\
\text { AD, } \alpha \text { 2agonist }\end{array}$ & $\begin{array}{l}\text { Response rates ( } 8 \text { weeks): } 70.6 \% \\
\text { (YMRS), 59.3\% [CGI]. Remission: } \\
46.7 \% \text {. }\end{array}$ & $\begin{array}{l}\text { Polydipsia, polyuria, emesis, } \\
\text { headache, tremor, } \uparrow \text { appetite }\end{array}$ \\
\hline [42] & $\begin{array}{l}\text { Prospective non- } \\
\text { randomized } \\
\text { cohort }\end{array}$ & 38 & $\begin{array}{l}\text { Mean serum levels, } 0.83 \mathrm{mmol} / \mathrm{L} \text { (at } \\
\text { the end of the study); Mean dose, } \\
872 \mathrm{mg} / \text { day; DVPX: Mean serum } \\
\text { level achieved, } 75.5 \mathrm{ug} / \mathrm{mL} \text { (at the } \\
\text { end of the study); Mean dose } \\
833 \mathrm{mg} / \text { day }\end{array}$ & $\begin{array}{l}\text { MPH, } \\
\text { olanzapine, } \\
\text { risperidone, } \\
\text { clonidine }\end{array}$ & $\begin{array}{l}89.5 \%(34 / 38) \text { pts responded to } \\
\text { treatment with } \mathrm{Li}+/ \mathrm{DVPX} \text { mood } \\
\text { stabilizer therapy alone; four pts } \\
\text { required adjunctive antipsychotic } \\
\text { treatment to address residual } \\
\text { symptomatology; reinitiation of Li } \\
\text { +/DVPX combination therapy was } \\
\text { well tolerated with no pts } \\
\text { discontinuing because of a } \\
\text { medication-related adverse event. }\end{array}$ & $\begin{array}{l}\text { Emesis, enuresis, headache, } \\
\text { †appetite }\end{array}$ \\
\hline
\end{tabular}



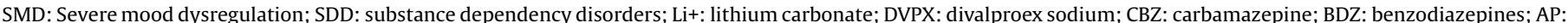

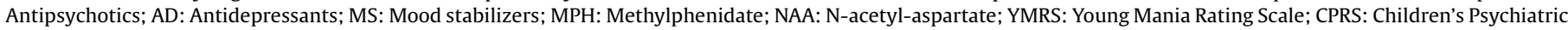



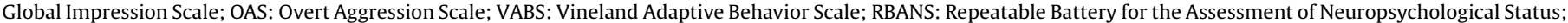

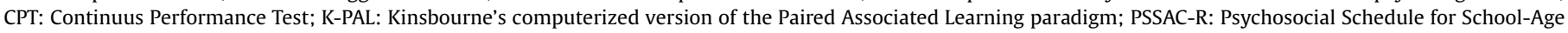



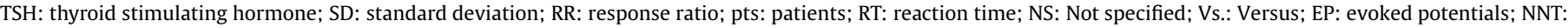
Number needed to treat; *Related to the use of lithium; RCT: Randomized controlled trial; Differences statistically significant (p<0.05). 
in restabilizing BD patients who had treated with combined lithium plus divalproex sodium but later relapsed with monotherapy of one agent [41,42].

\section{Starting dose and dosing strategy}

In patients with BD-I, two phases in the distribution of lithium was observed, with an initial half-life of $2.4 \mathrm{~h}$ and a later half-life of $27 \mathrm{~h} \mathrm{[43].} \mathrm{Multiple} \mathrm{dose} \mathrm{simulations} \mathrm{suggested} \mathrm{that} \mathrm{a} \mathrm{starting} \mathrm{dose}$ of $300 \mathrm{mg}$ once daily for those weighing less than $30 \mathrm{~kg}$, and $300 \mathrm{mg}$ twice or three times daily for youths weighing $30 \mathrm{~kg}$ or more, appear to be appropriate based on safety margins for trough concentrations. Later trials from the same research group observed a good tolerability of starting dose of $900 \mathrm{mg} /$ day for most subjects $[14,20]$.

\section{Brain-to-serum lithium association}

A cross-sectional study conducted on BD-I patients showed a positive correlation between serum and brain lithium concentrations, with younger subjects having lower brain-to-serum concentration ratios than adults $(0.58, \mathrm{SD}=0.24 \mathrm{vs} .0 .92, \mathrm{SD}=0.36)$ [44]. According to these results, children and adolescents may need higher maintenance serum lithium concentrations than adults to reach similar brain lithium concentrations.

\section{Safety and tolerability}

Lithium's recommended target dose in children and adolescents is $30 \mathrm{mg} / \mathrm{kg} /$ day, with $0.6-1.2 \mathrm{mEq} / \mathrm{L}$ serum levels [45] even though other authors [14,20] suggest more aggressive dosing, particularly for acute manic or mixed episodes. For instance, the FDA recommends dosing lithium until therapeutic response or a maximal blood level of $1.4 \mathrm{mEq} / \mathrm{L}$ is achieved or a dose-limiting side effect is present. Studies in this review tended to be within those guidelines, with $10-30 \mathrm{mg} / \mathrm{kg} /$ day dosages range, $0.6-1.5$ $\mathrm{mEq} / \mathrm{L}$ serum levels (Table 1 ). Most of the selected studies reported side effects in the mild to moderate range, with low dropout rates. No serious adverse events were reported either with lithium monotherapy or in combination with other psychotropic drugs (Table 1). Obviously, close serum level monitoring is required to ensure that lithium is safe and well-tolerated.

The most common side effects of lithium in children and adolescents were gastrointestinal symptoms (including nausea, vomiting, diarrhea, abdominal cramps, stomach pain), tremor, polyuria, polydipsia, and enuresis (Table 1 ). Only a minority of patients presented hypothyroidism with increased thyroid stimulating hormone [20] and/or thyroid enlargement [14,29]. Most of the studies report an increase in appetite and weight gain, which is a problem with several other BD agents [46]. However, this difference was not statistically different from placebo [20]. No cases of acute kidney injury or chronic kidney disease were reported.

\section{Discussion}

This study is the first systematic review to look specifically at the use of lithium in children and adolescents with BD. Thirty studies were included. Almost sixty percent of subjects were studied in RCTs ( $\mathrm{n}=12$ studies) that evaluated lithium efficacy in acute manic-mixed episodes, and as a prophylactic agent. Lithium was effective in monotherapy and in combination with antipsychotics for treating acute manic and mixed episodes. Lithium showed a greater response in manic episodes without psychotic symptoms, and in the absence of ADHD comorbidity. Adolescents had a better response than prepubescent children, and prophylactic efficacy was superior to divalproex and proportional to acute response [31]. Lithium also was effective in treating BD with secondary substance use disorder.

It is unclear whether lithium is effective in treating bipolar depression in children and adolescents. The only study that evaluated lithium efficacy on bipolar depression in youth [28] found relatively low response rates that are in line with previous results in depressed children with a family history of BD [16] and in adults [47].

Lithium appears generally safe for use by children and adolescents with only mild-moderate side effects. Its long-term risks also do not appear to be notable, at least as identified so far, and seem consistent with the adult literature. No cases of renal failure were observed in the sample of over 2000 subjects included in this systematic review, but this is probably explained by the short follow-up. In fact, accordingly to the literature, long-term patients (generally after 10-20 years of treatment) have an increased risk to develop impaired renal function due to a slowly progressive chronic interstial nephritis. Hypothyroidism was observed, though only in a minority of patients.

All the RCTs that found a lower efficacy of lithium compared to risperidone $[26,35,37,38]$ were from the Treatment of Early Age Mania Study (TEAM).

\subsection{Epidemiological and clinical background of $B D$ in children and adolescents}

In the past, with the exception of a few experts, like Kraepelin and Ziehen, bipolar illness in children essentially was not considered a diagnostic possibility until recently. Estimated prevalence in adolescence varies from 1.8\% [48] to 2.5\% [49], being slightly higher in the US than in Europe. In 2011, the World Health Organization listed bipolar spectrum disorder as the fourth leading cause of disability among adolescent ages 15-19 years worldwide [50]. Annual rates of BD diagnosis [51] and related hospitalization [52] in youth are increasing. Compared to adultonset $\mathrm{BD}$, children and adolescents experience more symptoms, comorbidities and mood switches and have a poorer prognosis $[53,54]$. Because BD is a recurrent condition with more than $70 \%$ of subjects relapsing by early adulthood [55], it is important to treat prophylactically even in childhood, when it is often misdiagnosed [56] or left untreated [57].

\subsection{Comparison with FDA recommendations and main guidelines}

In the paediatric population, lithium is the only mood stabilizer with a US Food and Drug Administration (FDA) indication for acute mania and maintenance treatment of $\mathrm{BD}$ and it is licensed for treatment of acute mania in the UK [58,59]. Clinicians still display qualms about lithium [60,61], with BD children and adolescents receiving complex treatment regimens, often involving multiple psychotropic drugs; only $2 \%$ receive lithium monotherapy [62].

Effective treatments in BD youths are still withheld or underused. More than one third of children with $\mathrm{BD}$ receive two or more medications belonging to different classes (i.e. mood stabilizers, antipsychotics, antidepressants or stimulants) feeding the problem of off-label prescriptions [63].

The US FDA also has approved risperidone, aripiprazole, quetiapine, olanzapine, olanzapine in association with fluoxetine, lurasidone and asenapine for the treatment of $\mathrm{BD}$ in youth; the higher efficacy of risperidone above lithium in the two trials available might have been driven by the high comorbidity rates in the study populations, or it may reflect more rapid acute onset of effect [58]. Aripiprazole, the only antipsychotic licensed in the UK for paediatric BD, is comparable in efficacy to traditional mood stabilizers [64]. 


\subsection{Tolerability}

Many second-generation antipsychotics are associated with a greater burden of metabolic side effects that, along with the recent warning about the use of antipsychotic in children and adolescents, could argue in favour of mood stabilizers [65-67]. In fact, lithium side effects (e.g. nausea, hand tremor, thirst and polyuria, diarrhoea) are dose-dependent and, although relatively frequent [68], are only mild-moderate in effect size. Cognitive effects also need to be considered, with a recent study finding impairment in executive control in adolescents treated with lithium [69]; another prior study did not find such cognitive impairment though [70]. Lithium treatment in adolescents is associated with an increase in blood TSH levels in up to $25 \%$ of the subjects [71]. In this systematic review, only one subject had clinically significant thyroid impairment.

It also is important to note that no cases of acute kidney injury or chronic kidney disease were observed. Still, serial monitoring of renal and thyroid functioning is recommended [71,72].

In sum, special concern about the use of lithium in children and adolescents, at least on safety grounds, seems unwarranted based on this systematic review.

\section{Limitations}

The main limitation of this systematic review is linked to the characteristics of the selected studies, such as brevity of follow-up periods, small sample sizes, and analysis strategies (Table 1). Small sample sizes and enrolment of subjects mainly from US sites (almost 94\%) may limit generalizability. Potential confounding factors in these studies include demographic and historical illness variables in non-randomized trials, which often were not appropriately analysed through multivariate modelling. The inclusion of only BD studies might limit the results regarding lithium tolerability in children and adolescents [11,12].

The main strength of this systematic review is linked to the inclusion of 12 RCTs (Table 1), which would limit the effect of confounding variables Further, this review was systematic, including the entire scientific evidence published so far. Also, diagnoses were consistently based on DSM criteria and were established by trained investigators using validated assessment scales mainly with interrater reliability. This is particularly relevant because one of the main features of BD is mood instability and it is easy to attribute mood swings to the behavioural vicissitudes of adolescence or to psychosocial changes [73]. Moreover the comorbidity rate in BD in youth is more than $80 \%$ [74-76], with up to $50 \%$ for anxiety disorders [77]. Thus, in mild cases, adjustment disorders are frequently diagnosed [78]. The debate about the possibility of broadening the diagnosis of BD in youth to a larger spectrum remains open [79]. Future studies should better define this diagnostic spectrum in order to allow better study of drug efficacy.

\section{Clinical implications}

The results of this systematic review, showing efficacy and safety of lithium in children with BD, are in line with clinical recommendations in literature. According to guidelines for children and adolescents with BD $[80,75,76]$, lithium is considered a first line treatment and can be prescribed in monotherapy for up to 8 weeks, if there are no psychotic features. If there are psychotic features, treatment combining a mood stabilizer and an antipsychotic is recommended.

Lithium should be considered if there is a comorbid substance use disorder, which has high frequency in this population and portends poor prognosis [10].
Overall, these results in children somehow overlap with those in adults which find efficacy with lithium [81,82], benefit with lithium in preventing suicide [83], and general tolerability of lithium [5]. Similarly, when accounting for body size, the pharmacokinetic parameters in paediatric patients were within the range of estimates from adults [21]. As in adults [84], lithium discontinuation in BD after successful maintenance monotherapy is not advisable.

Moreover, children who are treated with lithium are less likely to show mood instability, impulsivity and self-injurious behaviour, identity confusion, and interpersonal problems [60], all of which are poor prognostic factors [85].

To date, the field of child and adolescent psychiatry lacks validated prophylactic therapy for depressive and bipolar illness, and little is known about the benefit-cost ratio of long-term treatment with lithium. Progress in this area would serve to shed light on the best balance between efficacy and side effects in clinical settings. Future research efforts may lead to more grounded guidelines, which are greatly needed in child and adolescent psychiatry.

\section{Contributors}

Authors AA, AO, JC, MT, CM and SNG designed the study and wrote the protocol. Studies were identified and independently reviewed for eligibility by two authors (AA, FS) in a two-step based process. Data were extracted by two authors (AA, FS) and supervised by a third author (SNG) using an ad-hoc developed data extraction spreadsheet. Authors AA, PO, AO, MA, AC and SNG wrote the first draft of the manuscript. Our manuscript has been approved by all authors.

\section{Funding}

This research received no specific grant from any funding agency in the public, commercial or not-for-profit sectors.

\section{Competing interests}

Dr. Amerio, Dr. Ossola, Dr. Scagnelli, Dr. Odone, Dr. Allinovi, Dr. Cavalli, Dr. Iacopelli, Dr. Tonna, and Dr. Marchesi report no conflicts of interest. Dr. Ghaemi has provided research consulting to Sunovion in the past year, and is employed by Novartis Institutes for Biomedical Research. Neither he nor his family hold equity positions in pharmaceutical corporations.

\section{Acknowledgements}

The authors would like to thank Luigi Rolli for his help and support.

\section{Appendix A. Supplementary data}

Supplementary material related to this article can be found, in the online version, at doi: https://doi.org/10.1016/j. eurpsy.2018.07.012.

\section{References}

[1] Goldstein B.I., Birmaher B, Carlson GA, DelBello MP, Findling RL, Fristad M, et al. The International Society for Bipolar Disorders Task Force report on pediatric bipolar disorder: knowledge to date and directions for future research. Bipolar Disord 2017;19:524-43.

[2] Singh MK, Ketter T, Chang KD. Distinguishing bipolar disorder from other psychiatric disorders in children. Curr Psychiatry Rep 2014;16:516.

[3] Schneider C, Taylor D, Zalsman G, Frangou S, Kyriakopoulos M. Antipsychotics use in children and adolescents: an on-going challenge in clinical practice. J Psychopharmacol 2014;28:615-23. 
[4] Findling RL. Safety and tolerability of bipolar disorder treatment in youth. J Clin Psychiatry 2009;70:e44.

[5] McKnight RF, Adida M, Budge K, Stockton S, Goodwin GM, Geddes JR. Lithium toxicity profile: a systematic review and meta-analysis. Lancet 2012;379:7218.

[6] Amerio A, Galvéz JF, Odone A, Dalley SA, Ghaemi SN. Carcinogenicity of psychotropic drugs: a systematic review of FDA-required preclinical in vivo studies. Aust N Z J Psychiatry 2015;49:686-96.

[7] Marchesi C, Ossola P, Amerio A, Daniel BD, Tonna M, De Panfilis C. Clinical management of perinatal anxiety disorders: a systematic review. J Affect Disord 2015;190:543-50.

[8] Higgins J, Green S. Cochrane handbook for systematic reviews of interventions, version 5.1.0.. The Cochrane Collaboration; 2011.

[9] Liberati A, Altman DG, Tetzlaff J, Mulrow C, Gøtzsche PC, Ioannidis JP, et al. The PRISMA statement for reporting systematic reviews and meta-analyses of studies that evaluate healthcare interventions: explanation and elaboration. BMJ 2009;339: b2700.

[10] Dickstein DP, Towbin KE, Van Der Veen JW, Rich BA, Brotman MA, Knopf L, et al. Randomized double-blind placebo-controlled trial of lithium in youths with severe mood dysregulation. J Child Adolesc Psychopharmacol 2009;19:61-73.

[11] Campbell M, Silva RR, Kafantaris V, Locascio JJ, Gonzalez NM, Lee D, et al. Predictors of side effects associated with lithium administration in children. Psychopharmacol Bull 1991;27(3):373-80.

[12] Malone RP, Delaney MA, Luebbert JF, Cater J, Campbell M. A double-blind placebo-controlled study of lithium in hospitalized aggressive children and adolescents with conduct disorder. Arch Gen Psychiatry 2000;57:649-54.

[13] Erwin CW, Gerber CJ, Morrison SD, James JF. Lithium carbonate and convulsive disorders. Arch Gen Psychiatry 1973;28:646-8.

[14] Findling RL, Kafantaris V, Pavuluri M, McNamara NK, McClellan J, Frazier JA, et al. Dosing strategies for lithium monotherapy in children and adolescents with bipolar I disorder. J Child Adolesc Psychopharmacol 2011;21:195-205.

[15] Geller B, Cooper TB, Sun K, Zimerman B, Frazier J, Williams M, et al. Doubleblind and placebo-controlled study of lithium for adolescent bipolar disorders with secondary substance dependency. J Am Acad Child Adolesc Psychiatry 1998; $37: 171-8$.

[16] Geller B, Cooper TB, Zimerman B, Frazier J, Williams M, Heath J, et al. Lithium for prepubertal depressed children with family history predictors of future bipolarity: a double-blind, placebo-controlled study. J Affect Disord 1998:51:165-75.

[17] Kafantaris V, Coletti DJ, Dicker R, Padula G, Kane JM. Adjunctive antipsychotic treatment of adolescents with bipolar psychosis. J Am Acad Child Adolesc Psychiatry 2001;40:1448-56.

[18] Kafantaris V, Dicker R, Coletti DJ, Kane JM. Adjunctive antipsychotic treatment is necessary for adolescents with psychotic mania. J Child Adolesc Psychopharmacol 2001;11:409-13.

[19] Drotar D, Greenley RN, Demeter CA, et al. Adherence to pharmacological treatment for juvenile bipolar disorder. J Am Acad Child Adolesc Psychiatry 2007;46:831-9.

[20] Findling RL, Robb A, McNamara NK, Stansbrey RJ, Calabrese JR, et al. Lithium in the acute treatment of bipolar I disorder: a double-blind, placebo-controlled study. Pediatrics 2015;136:885-94.

[21] Landersdorfer CB, Findling RL, Frazier JA, Kafantaris V, Kirkpatrick CM. Lithium in paediatric patients with bipolar disorder: implications for selection of dosage regimens via population Pharmacokinetics/Pharmacodynamics. Clin Pharmacokinet 2017;56:77-90.

[22] Kafantaris V, Coletti D, Dicker R, Padula G, Kane JM. Lithium treatment of acute mania in adolescents: a large open trial. J Am Acad Child Adolesc Psychiatry 2003;42:1038-45.

[23] Strober M, Morrell W, Burroughs J, Lampert C, Danforth H, Freeman R. A family study of bipolar I disorder in adolescence. Early onset of symptoms linked to increased familial loading and lithium resistance. J Affect Disord 1988;15:25568.

[24] Kafantaris V, Coletti DJ, Dicker R, Padula G, Pollack S. Are childhood psychiatric histories of bipolar adolescents associated with family history, psychosis, and response to lithium treatment? J Affect Disord 1998;51:153-64.

[25] Kafantaris V, Coletti DJ, Dicker R, Padula G, Pleak PR, Alvir JM. Lithium treatment of acute mania in adolescents: a placebo-controlled discontinuation study. J Am Acad Child Adolesc Psychiatry 2004;43:984-93.

[26] Vitiello B, Riddle MA, Yenokyan G, Axelson DA, Wagner KD, Joshi P, et al. Treatment moderators and predictors of outcome in the Treatment of Early Age Mania (TEAM) study. J Am Acad Child Adolesc Psychiatry 2012;51:867-78.

[27] Strober M, DeAntonio M, Schmidt-Lackner S, Freeman R, Lampert CC, Diamond J. Early childhood attention deficit hyperactivity disorder predicts poorer response to acute lithium therapy in adolescent mania. J Affect Disord 1998;51:145-51.

[28] Patel NC, DelBello MP, Bryan HS, Adler CM, Kowatch RA, Stanford K, et al. Openlabel lithium for the treatment of adolescents with bipolar depression. J Am Acad Child Adolesc Psychiatry 2006;45:289-97.

[29] DeLong GR, Aldershof AL. Long-term experience with lithium treatment in childhood: correlation with clinical diagnosis. J Am Acad Child Adolesc Psychiatry 1987;26:389-94.

[30] Strober M, Morrell W, Lampert C, Burroughs J. Relapse following discontinuation of lithium maintenance therapy in adolescents with bipolar I illness: a naturalistic study. Am J Psychiatry 1990;147:457-61.
[31] Findling RL, Kafantaris V, Pavuluri M, McNamara NK, Frazier JA, Sikich L, et al. Post-acute effectiveness of lithium in pediatric bipolar I disorder. J Child Adolesc Psychopharmacol 2013;23:80-90.

[32] Jairam R, Srinath S, Girimaji SC, Seshadri SP. A prospective 4-5 year follow-up of juvenile onset bipolar disorder. Bipolar Disord 2004;6:386-94.

[33] McKnew DH, Cytryn L, Buchsbaum MS, Hamovit J, Lamour M, Rapoport JL, et al. Lithium in children of lithium-responding parents. Psychiatry Res 1981;4:17180.

[34] Findling RL, McNamara NK, Youngstrom EA, Stansbrey R, Gracious BL, Reed $\mathrm{MD}$, et al. Double-blind 18-month trial of lithium versus divalproex maintenance treatment in pediatric bipolar disorder. J Am Acad Child Adolesc Psychiatry 2005;44:409-17.

[35] Geller B, Luby JL, Joshi P, Wagner KD, Emslie G, Walkup JT, et al. A randomized controlled trial of risperidone, lithium, or divalproex sodium for initial treatment of bipolar I disorder, manic or mixed phase, in children and adolescents. Arch Gen Psychiatry 2012;69:515-28.

[36] Kowatch RA, Suppes T, Carmody TJ, Bucci JP, Hume JH, Kromelis M, et al. Effect size of lithium, divalproex sodium, and carbamazepine in children and adolescents with bipolar disorder. J Am Acad Child Adolesc Psychiatry 2000;39:713-20.

[37] Salpekar JA, Joshi PT, Axelson DA, Reinblatt SP, Yenokyan G, Sanyal A, et al Depression and suicidality outcomes in the treatment of early age mania study. J Am Acad Child Adolesc Psychiatry 2015;54:999-1007 e1004.

[38] Walkup JT, Wagner KD, Miller L, Yenokyan G, Luby JL, Joshi PT, et al. Treatment of early-age mania: outcomes for partial and nonresponders to initial treatment. J Am Acad Child Adolesc Psychiatry 2015;54:1008-19.

[39] Kowatch RA, Sethuraman G, Hume JH, Kromelis M, Weinberg WA. Combination pharmacotherapy in children and adolescents with bipolar disorder. Biol Psychiatry 2003;53:978-84.

[40] Pavuluri MN, Henry DB, Carbray JA, Sampson G, Naylor NW, Janicak PG. Openlabel prospective trial of risperidone in combination with lithium or divalproex sodium in pediatric mania. J Affect Disord 2004;82(Suppl. 1):S103111.

[41] Findling RL, McNamara NK, Gracious BL, Youngstrom EA, Stansbrey RJ, Reed $\mathrm{MD}$, et al. Combination lithium and divalproex sodium in pediatric bipolarity. J Am Acad Child Adolesc Psychiatry 2003;42:895-901.

[42] Findling RL, McNamara NK, Stansbrey R, Gracious BL, Whipkey RE, Demeter $\mathrm{CA}$, et al. Combination lithium and divalproex sodium in pediatric bipolar symptom re-stabilization. J Am Acad Child Adolesc Psychiatry 2006:45:142-8.

[43] Findling RL, Landersdorfer CB, Kafantaris V, Pavuluri M, McNamara NK, McClellan J, et al. First-dose pharmacokinetics of lithium carbonate in children and adolescents. J Clin Psychopharmacol 2010;30:404-10.

[44] Moore CM, Demopulos CM, Henry ME, Steingard RJ, Zamvil L, Katic A, et al. Brain-to-serum lithium ratio and age: an in vivo magnetic resonance spectroscopy study. Am J Psychiatry 2002;159:1240-2.

[45] Martin ASL, Charney DS, Leckman JF. Pediatric psychopharmacology: principles and practice. New York: Oxford University Press; 2003.

[46] Findling RL, Chang KD. Improving the diagnosis and treatment of pediatric bipolar disorder. J Clin Psychiatry 2018;79:62-9.

[47] Selle V, Schalkwijk S, Vazquez GH, Baldessarini RJ. Treatments for acute bipolar depression: meta-analyses of placebo-controlled, monotherapy trials of anticonvulsants, lithium and antipsychotics. Pharmacopsychiatry 2014;47:43-52.

[48] Van Meter AR, Moreira AL, Youngstrom EA. Meta-analysis of epidemiologic studies of pediatric bipolar disorder. J Clin Psychiatry 2011;72:1250-6.

[49] Merikangas KR, Cui L, Kattan G, Carlson GA, Youngstrom EA, Angst J. Mania with and without depression in a community sample of US adolescents. Arch Gen Psychiatry 2012;69:943-51.

[50] Gore FM, Bloem PJ, Patton GC, Ferguson J, Joseph V, Coffey C, et al. Global burden of disease in young people aged 10-24 years: a systematic analysis. Lancet 2011;377:2093-102.

[51] Blader JC, Carlson GA. Increased rates of bipolar disorder diagnoses among U.S. child, adolescent, and adult inpatients, 1996-2004. Biol Psychiatry 2007;62:107-14.

[52] Shapiro J, Timmins V, Swampillai B, Scavone A, Collinger K, Boulos C, et al Correlates of psychiatric hospitalization in a clinical sample of Canadian adolescents with bipolar disorder. Compr Psychiatry 2014;55:1855-61.

[53] Baldessarini RJ, Tondo L, Vazquez GH, Undurraga J, Bolzani L, Yildiz A, et al. Age at onset versus family history and clinical outcomes in 1,665 international bipolar-I disorder patients. World Psychiatry 2012;11:40-6.

[54] Holtzman JN, Miller S, Hooshmand F, Wang PW, Chang KD, Hill SJ, et al. Childhood-compared to adolescent-onset bipolar disorder has more statistically significant clinical correlates. J Affect Disord 2015;179:114-20.

[55] Geller B, Tillman R, Bolhofner K, Zimerman B. Child bipolar I disorder: prospective continuity with adult bipolar I disorder; characteristics of second and third episodes; predictors of 8-year outcome. Arch Gen Psychiatry 2008;65:1125-33.

[56] Baethge C, Glovinsky I, Baldessarini RJ. Manic-depressive illness in children: an early twentieth-century view by Theodor Ziehen (1862-1950). Introduction. Hist Psychiatry 2004;15:201-26.

[57] Khazanov GK, Cui L, Merikangas KR, Angst J. Treatment patterns of youth with bipolar disorder: results from the National Comorbidity Survey-Adolescent Supplement (NCS-A). J Abnorm Child Psychol 2015;43:391-400.

[58] Giles LL, Martini DR. Challenges and promises of pediatric psychopharmacology. Acad Pediatr 2016;16:508-18. 
[59] Goodwin GM, Haddad PM, Ferrier IN, Aronson JK, Barnes T, Cipriani A, et al. Evidence-based guidelines for treating bipolar disorder: revised third edition recommendations from the British Association for Psychopharmacology. J Psychopharmacol 2016;30:495-553.

[60] Ko A, Swampillai B, Timmins V, Scavone A, Collinger K, Goldstein BI. Clinical characteristics associated with lithium use among adolescents with bipolar disorder. J Child Adolesc Psychopharmacol 2014;24:382-9.

[61] Strejilevich SA, Urtueta-Baamonde M, Teitelbaum J, Martino DJ, Marengo E, Igoa A, et al. [Clinical concepts associated with lithium underutilization in the treatment of bipolar disorder]. Vertex 2011;22: Suppl: 3-20.

[62] Dusetzina SB, Weinberger M, Gaynes BN, Farley JF, Sleath B, Hansen RA Prevalence of bipolar disorder diagnoses and psychotropic drug therapy among privately insured children and adolescents. Pharmacotherapy 2012;32:1085-94.

[63] Sharma AN, Arango C, Coghill D, Gringras P, Nutt DJ, Pratt P, et al. BAP Position Statement: off-label prescribing of psychotropic medication to children and adolescents. J Psychopharmacol 2016;30:416-21.

[64] Meduri M, Gregoraci G, Baglivo V, Balestrieri M, Isola M, Brambilla P. A metaanalysis of efficacy and safety of aripiprazole in adult and pediatric bipolar disorder in randomized controlled trials and observational studies. J Affect Disord 2016;191:187-208.

[65] Correll CU, Detraux J, De Lepeleire J, De Hert M. Effects of antipsychotics, antidepressants and mood stabilizers on risk for physical diseases in people with schizophrenia, depression and bipolar disorder. World Psychiatry 2015:14:119-36.

[66] DelBello MP, Correll CU. Primum non nocere: balancing the risks and benefits of prescribing psychotropic medications for youth with bipolar disorder. Bipolar Disord 2010;12:113-5.

[67] Samaras K, Correll CU, Mitchell AJ, De Hert M. Diabetes risk potentially underestimated in youth and children receiving antipsychotics. JAMA Psychiatry 2014;71:209-10.

[68] Licht RW, Vestergaard P, Kessing LV, Larsen JK, Thomsen PH. Psychopharmacological treatment with lithium and antiepileptic drugs: suggested guidelines from the Danish Psychiatric Association and the Child and Adolescent Psychiatric Association in Denmark. Acta Psychiatr Scand Suppl 2003;1-22.

[69] Lera-Miguel S, Andres-Perpina S, Fatjo-Vilas M, Fañanás L, Lázaro L. Two-year follow-up of treated adolescents with early-onset bipolar disorder: changes in neurocognition. J Affect Disord 2015;172:48-54.

[70] Muralidharan K, Kozicky JM, Bucker J, Silveira LE, Torres IJ, Yatham LN. Are cognitive deficits similar in remitted early bipolar I disorder patients treated with lithium or valproate? Data from the STOP-EM study. Eur Neuropsychopharmacol 2015;25:223-30.

[71] Amitai M, Zivony A, Kronenberg S, Nagar L, Saar S, Sever J, et al. Short-term effects of lithium on white blood cell counts and on levels of serum thyroid- stimulating hormone and creatinine in adolescent inpatients: a retrospective naturalistic study. J Child Adolesc Psychopharmacol 2014;24:494-500.

[72] Scahill L, Farkas L, Hamrin V. Lithium in children and adolescents. J Child Adolesc Psychiatr Nurs 2001:14:89-93.

[73] Harrison PJ, Cipriani A, Harmer CJ, Nobre AC, Saunders K, Goodwin GM, et al. Innovative approaches to bipolar disorder and its treatment. Ann N Y Acad Sci 2016;1366:76-89.

[74] Birmaher B, Axelson D, Goldstein B, Strober M, Gill MK, Hunt J, et al. Four-year longitudinal course of children and adolescents with bipolar spectrum disorders: the course and outcome of bipolar youth (COBY) study. Am J Psychiatry 2009;166:795-804.

[75] Kowatch RA, Fristad M, Birmaher B, Wagner KD, Findling RL, Hellander M. Treatment guidelines for children and adolescents with bipolar disorder. J Am Acad Child Adolesc Psychiatry 2005;44:213-35.

[76] Kowatch RA, Youngstrom EA, Danielyan A, Findling RL. Review and metaanalysis of the phenomenology and clinical characteristics of mania in children and adolescents. Bipolar Disord 2005;7:483-96.

[77] Frias A, Palma C, Farriols N. Comorbidity in pediatric bipolar disorder: prevalence, clinical impact, etiology and treatment. J Affect Disord 2015; 174:378-89.

[78] Kessing LV, Vradi E, McIntyre RS, Andersen PK. Causes of decreased life expectancy over the life span in bipolar disorder. J Affect Disord 2015;180:142 7.

[79] Birmaher B, Gill MK, Axelson DA, Goldstein BI, Goldstein TR, Yu H, et al. Longitudinal trajectories and associated baseline predictors in youths with bipolar spectrum disorders. Am J Psychiatry 2014;171:990-9.

[80] McClellan J, Kowatch R, Findling RL. Practice parameter for the assessment and treatment of children and adolescents with bipolar disorder. J Am Acad Child Adolesc Psychiatry 2007;46:107-25.

[81] Miura T, Noma H, Furukawa TA, Mitsuyasu H, Tanaka S, Stockton S, et al. Comparative efficacy and tolerability of pharmacological treatments in the maintenance treatment of bipolar disorder: a systematic review and network meta-analysis. Lancet Psychiatry 2014;1:351-9.

[82] Lähteenvuo M, Tanskanen A, Taipale H, Hoti F, Vattulainen P, Vieta E, et al. Realworld effectiveness of pharmacologic treatments for the prevention of rehospitalization in a finnish nationwide cohort of patients with bipolar disorder. JAMA Psychiatry 2018;75:347-55.

[83] Cipriani A, Hawton K, Stockton S, Geddes JR. Lithium in the prevention of suicide in mood disorders: updated systematic review and meta-analysis. BMJ 2013;346: f3646.

[84] Biel MG, Peselow E, Mulcare L, Case BG, Fieve R. Continuation versus discontinuation of lithium in recurrent bipolar illness: a naturalistic study. Bipolar Disord 2007;9:435-42.

[85] Miklowitz DJ. Functional impairment, stress, and psychosocial intervention in bipolar disorder. Curr Psychiatry Rep 2011;13:504-12. 